Wright State University

CORE Scholar

$10-1-2006$

\title{
Morphology of the Near-Terminator Martian lonosphere: A Comparison of Models and Data
}

Jane L. Fox

Wright State University - Main Campus, jane.fox@wright.edu

Katherine E. Yeager

Follow this and additional works at: https://corescholar.libraries.wright.edu/physics

Part of the Physics Commons

\section{Repository Citation}

Fox, J. L., \& Yeager, K. E. (2006). Morphology of the Near-Terminator Martian Ionosphere: A Comparison of Models and Data. Journal of Geophysical Research-Space Physics, 111, A10309.

https://corescholar.libraries.wright.edu/physics/26

This Article is brought to you for free and open access by the Physics at CORE Scholar. It has been accepted for inclusion in Physics Faculty Publications by an authorized administrator of CORE Scholar. For more information, please contact library-corescholar@wright.edu. 


\title{
Morphology of the near-terminator Martian ionosphere: A comparison of models and data
}

\author{
J. L. Fox ${ }^{1}$ and Katherine E. Yeager ${ }^{1}$ \\ Received 28 February 2006; revised 22 May 2006; accepted 7 July 2006; published 19 October 2006.
}

[1] We have constructed low and high solar activity models of the Martian thermosphere/ ionosphere for solar zenith angles from 60 to $90^{\circ}$ in 5 degree increments. The solar fluxes that we have adopted are those from the Solar 2000 v2.22 models of Tobiska (2004), without enhancements of the soft X-ray fluxes. The background neutral density and temperature profiles are similar to those that we have recently presented (Fox, 2004). We compute the density profiles for 14 ions and nine neutral species. For all the models, we present altitude profiles of the photoionization rates, electron impact ionization rates, total ion production rates, and the predicted electron density profiles. Each model exhibits both an $F_{1}$ peak and an $E$ peak, although the latter usually appears as a shoulder, rather than as a separate peak. The altitudes of the model peaks are found to be slightly too high. We fit the model peak densities to the equation $n_{\max , \chi}^{i}=A(\cos \chi)^{k}$, where, for an ideal Chapman layer, $A$ is the value of the subsolar peak density, $n_{\max , 0}^{i}$, and the exponent $k$ is 0.5 . We compare the behavior of the model electron density profiles to that of a theoretical Chapman layer and to the values of $A$ and $k$ obtained by fitting the Mars Global Surveyor (MGS) radio science electron density profiles for occultation seasons 1,2 , and 4 . We also compare our results to those of previous investigators who have analyzed data from earlier Mars missions and those from MGS and from the Mars Express spacecraft. We find that our model best fit values of $k$ for the $F_{1}$ peak and those derived from the MGS data are less than the Chapman value of 0.5 . We note, however, that the use of spherical geometry alone reduces the value of $k$ below the Chapman value for large solar zenith angles, but the deviation from the experimental values also indicates that there are changes in the neutral atmosphere as the terminator is approached. Our peak densities and predicted subsolar peak densities for both the $F_{1}$ and $E$ peaks are somewhat smaller than those derived from the data. This is attributed to the use of the S2K v2.22 solar flux models, rather than the S2K v1.24 models or those from Hinteregger (1981). We also evaluate the neutral, ion, and plasma pressure scale heights at the peaks, $33 \mathrm{~km}$ above the peaks and at $250 \mathrm{~km}$ for all the models. We find that the solar activity variation of our peak densities are in substantial agreement with those determined by other investigators. We argue that the peaks near $90^{\circ}$ solar zenith angle are above the photochemical equilibrium region and fitting these peaks to a Chapman profile is therefore inappropriate.

Citation: Fox, J. L., and K. E. Yeager (2006), Morphology of the near-terminator Martian ionosphere: A comparison of models and data, J. Geophys. Res., 111, A10309, doi:10.1029/2006JA011697.

\section{Introduction}

[2] Electron density profiles of the Martian ionosphere have been recorded by radio occultation experiments aboard several space probes, including Mariners 4, 6, and 7 [e.g., Fjeldbo and Eshleman, 1968; Fjeldbo et al., 1970; Hogan et al., 1972], Mariner 9 [e.g., Kliore et al., 1972a, 1972b, 1973], Mars 2, 3, 4, and 6 [Kolosov et al., 1972, 1973; Vasilev et al., 1975], Vikings 1 and 2 [e.g., Lindal et al.,

${ }^{1}$ Department of Physics, Wright State University, Dayton, Ohio, USA.

Copyright 2006 by the American Geophysical Union. 0148-0227/06/2006JA011697
1979; Zhang et al., 1990], and more recently by the Mars Global Surveyor (MGS) [e.g., Tyler et al., 2001], and Mars Express (MEX) [e.g., Pätzold et al., 2005]. The Mariner 6 and 7 flybys entered the atmosphere during a period of moderately high solar activity $\left(F_{10.7} \sim 167\right.$ and 187.7, respectively) and at solar zenith angles of $\sim 56-57^{\circ}$. The Mariner 9 orbiter in the primary and extended missions probed the moderate solar activity ionosphere for solar zenith angles from $\sim 47$ to $100^{\circ}$, and the Viking orbiters sampled the low solar activity ionosphere in the solar zenith angle (SZA) range from about 53 to $93^{\circ}$. In addition, the Viking 1 and 2 landers, which entered the Martian atmosphere at very low solar activity $\left(F_{10.7} \sim 70\right)$, carried 


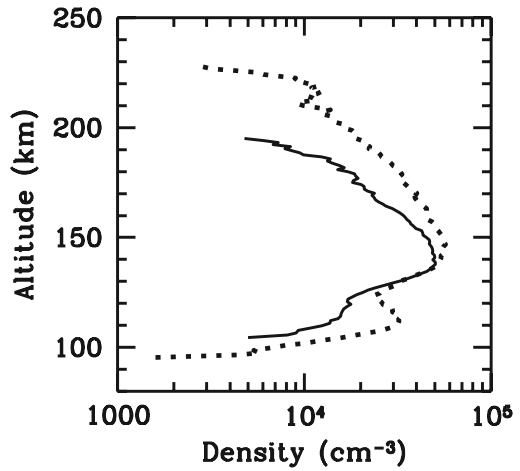

Figure 1. Representative Mars Global Surveyor (MGS) radio occultation profiles from adjacent days, which show very different lower peak morphologies. The two profiles are characterized by solar zenith angles of $\sim 86^{\circ}$ and latitudes near $63^{\circ}$. The dotted profile, which shows a very distinct lower peak, is that for 6 November 2000 (MGS profile identifier 0311U50A), and the solid curve, which shows only a lower shoulder is that for 7 November 2000 (MGS profile identifier 0312C43A).

Retarding Potential Analyzers (RPA), which measured the density profiles of the major ions in the atmosphere during their descent to the surface. The solar zenith angles at the ion peaks were $43-45^{\circ}$ [e.g., Hanson et al., 1977].

[3] The European Space Agency MEX spacecraft is currently orbiting Mars. In addition to the orbiter radio science experiment (MaRS) [e.g., Pätzold et al., 2005], the MEX spacecraft also carries a low frequency radar instrument called the Mars Advanced Radar for Subsurface and Ionospheric Sounding (MARSIS) [Gurnett et al., 2005]. Unlike radio occultation experiments, this instrument can only probe the topside of the ionosphere, the $F_{1}$ peak, and the total electron content of the atmosphere. Because it operates by vertical sounding, however, it is also capable of measuring the electron density profiles near the subsolar region. Radio occultation measurements are limited by geometry to solar zenith angles greater than $45^{\circ}$. The MaRS instrument probed the Martian ionosphere in two seasons at fairly low solar activity, April to August 2004 and December 2004 to January 2005. The first season consisted of 13 early morning profiles at solar zenith angles of 85 to $108^{\circ}$ and 77 evening profiles from 70 to $84^{\circ}$. Details of the $F_{1}$ and $E$ peaks are not yet available, but the instrument is reported to have observed two stable layers at $\sim 130$ and $\sim 110 \mathrm{~km}$. The MARSIS experiment probed the topside ionosphere from 5 July 2005 to 10 October 2005, a period of relatively low solar activity, for $F_{10.7}$ ranging from $\sim 70$ to 130 .

[4] The MGS radio science experiment has provided a comprehensive set of electron density profiles for the nearterminator Martian ionosphere in seven occultation seasons that date from December 1998 to March 2005. The data from these occultation seasons are available courtesy of D. Hinson and the MGS Radio Science Team on the public Web site: http://nova.stanford.edu/projects/mgs/eds-public. html. The MGS profiles for seasons 1, 2, and 4, were obtained at solar zenith angles of $\sim 71-87^{\circ}$. Most of the profiles have exhibited two peaks. An upper peak appears in the range $\sim 125-150 \mathrm{~km}$, and a lower peak or shoulder is observed in the range $\sim 105-135 \mathrm{~km}$. Figure 1 shows two representative MGS electron density profiles, which were measured on 6 and 7 November 2000, at nearly the same latitudes $\left(\sim 63^{\circ}\right)$ and solar zenith angles $\left(\sim 86^{\circ}\right)$. The profiles differ significantly on both the topside and the bottomside. In particular, the profile for 6 November 2000 shows a larger more distinct lower peak with a magnitude of about $3 \times 10^{4} \mathrm{~cm}^{-3}$, while that for 7 November 2000 shows only a lower shoulder with an estimated peak density of about $1.7 \times 10^{4} \mathrm{~cm}^{-3}$.

[5] We will here refer to the upper peak as an $F_{1}$ peak and to the lower peak as an $E$ peak. This convention is the same as that adopted by Bauer [1973] and by Banks and Kockarts [1977] for the terrestrial ionosphere. The sources of the $F_{1}$ peak are photoionization by EUV photons with wavelengths of $\sim 150-1000 \AA$ and the concomitant photoelectron impact ionization. The $E$ peak arises from the absorption of solar soft X-ray photons followed by ionization by the highenergy photoelectrons and secondary electrons that are produced. In the terrestrial ionosphere, ionization of $\mathrm{O}_{2}$ by solar Lyman $\beta$ at $1026 \AA$ contributes to the $E$ peak, but this source is not important in the ionosphere of Mars, where $\mathrm{O}_{2}$ is a minor constituent. For the lower peak, electron-impact ionization dominates, while for the upper peak, photoionization is more important [cf., Fox, 2004].

[6] The altitudes at which the peaks have been found to occur have been highly variable. This variability arises from several sources, other than that expected for changes in the solar zenith angle. The peak altitudes have been shown to vary with planetocentric longitude; this variation has been ascribed to planetary scale waves that originate in the lower atmosphere [e.g., Forbes and Hagan, 2000; Bougher et al., 2001; Wilson, 2002; Wilson et al., 2002; Forbes et al., 2002]. This wave activity causes oscillations in the pressure, temperature, and densities of the atmosphere up to altitudes of about 150-160 km [e.g., Keating et al., 1998]. For data from the first MGS occultation season, Bougher et al. [2001] fitted the mass densities at $130 \mathrm{~km}$, and the altitudes of the of the electron density peaks as a function of longitude with spherical harmonics up to wave-3. Bougher et al. [2004] analyzed the first five MGS occultation seasons and found strong wave number $2-3$ oscillations in the peak heights as a function of longitude. These oscillations were found to be repeatable over 2 Martian years.

[7] Some of the waves have their origin in topography [e.g., Lindal et al., 1979; Withers et al., 2003]. Kliore et al. [1972b], and more recently, Wang and Nielsen [2004] analyzed the Mariner 9 radio occultation data and showed that the altitude of the peaks rises and falls with the elevation of the surface. This effect has been suggested to be more pronounced at lower latitudes where the variations in the altitude of the surface are larger. Seasonal changes have been predicted to affect the peak altitude, with a variation of about $15 \mathrm{~km}$ from aphelion to perihelion [Bougher et al., 2000].

[8] The occurrence of planetwide dust storms has also been known to cause the altitude of the peaks in the electron density profiles to rise by as much as $30 \mathrm{~km}$. This is a result of heating due to absorption of solar energy by the dust particles in the lower atmosphere, which causes the atmosphere to expand, and the altitude of the base of the 
thermosphere to rise [e.g., Kliore et al., 1972b; Kliore et al., 1973; McElroy et al., 1977; Stewart, 1987; Keating et al., 1998; Wang and Nielsen, 2003].

[9] Wang and Nielsen [2004] have adduced evidence that the altitude of the electron density peak is modulated also by the interaction of the thermosphere/ionosphere with the solar wind. This mechanism for this interaction is suggested to be the precipitation of solar wind protons, which are predicted to deposit their energy at an altitude of $\sim 120 \mathrm{~km}$ [e.g., Kallio and Janhunen, 2001]. Wang and Nielsen showed that the altitude of the $F_{1}$ peak increases with the solar wind proton flux for low values of the proton flux but seems to saturate for proton fluxes greater than $\sim 3 \mathrm{~cm}^{-2} s^{-1} \mathrm{ster}^{-1}$. The effect is believed to be more pronounced at larger than at smaller solar zenith angles.

[10] Although the altitudes of the electron density peaks are determined by a number of factors other than photochemistry, the maximum number densities of the $E$ and $F_{1}$ peaks appear to be under solar control [e.g., Bauer and Hantsch, 1989; Zhang et al., 1990; Hantsch and Bauer, 1990; Fox et al., 1995; Martinis et al., 2003; Mendillo et al., 2003; Rishbeth and Mendillo, 2004]. The measured electron-density profiles have been compared to theoretical Chapman layers by several investigators. Chapman layer theory [Chapman, 1931a] specifically for ionospheres has been described in several textbooks [e.g., Rishbeth and Garriott, 1969; Bauer, 1973; Banks and Kockarts, 1977; Schunk and Nagy, 2000]. We therefore limit ourselves here to a brief presentation of the salient features and the most important equations to define the notation that we use here. These equations are used also to illustrate how the peak number densities change with variations in the parameters in Chapman theory.

[11] A Chapman ion layer is one that is produced by photoionization of a single molecular species, $\mathrm{XY}$, with a rate $q^{i}(z)$; the resulting molecular ion is destroyed locally by dissociative recombination: $\mathrm{XY}^{+}+\mathrm{e} \rightarrow \mathrm{X}+\mathrm{Y}$, with a rate coefficient $\alpha_{\mathrm{dr}}$. The ideal Chapman layer is produced by monochromatic radiation in an isothermal atmosphere, characterized by a temperature $T_{n}$. The production rate of the ions is given by

$$
q^{i}(z)=F(z) \sigma^{i} n(z),
$$

where $n(z)$ is the local number density, $\sigma^{i}$ is the photoionization cross section, $F(z)=F^{\infty} \exp [-\tau(z)]$ is the local ionizing solar photon flux, $F^{\infty}$ is the ionizing photon flux at the top of the atmosphere, and $\tau(z)$ is the optical depth. If the altitude dependence of the acceleration of gravity $g$ is ignored, the pressure scale height, which is given by the expression $H=k T / \mathrm{mg}$, where $m$ is the mass of the single constituent, is a constant and is equal to the neutral number density scale height, $H_{n}$. Thus the number density of the neutral species at altitude $z$ is given by $n(z)=n_{0} \exp (-z / H)$, where $n_{0}$ is the number density at a reference altitude, which may be defined as $z=0$.

[12] The maximum ionization rate in an isothermal atmosphere occurs where the optical depth $\left(\tau=n H \sigma^{a} \sec \chi\right)$ is unity. Here $\sigma^{a}$ is the total absorption cross section, $\chi$ is the solar zenith angle, and $n H \sec \chi=N \sec \chi$ is the slant column density. (Note that we here use $n$ as the local number density and reserve $N$ for the column density.)
For these conditions, the number density at unit optical depth, $n=1 /\left(\sigma^{a} H \sec \chi\right)$, so the maximum ionization rate in a Chapman layer is

$$
q_{\max , \chi}^{i}=\frac{F^{\infty}}{e} \frac{\sigma^{i}}{\sigma^{a} H \sec \chi}=\frac{q_{\max , 0}^{i}}{\sec \chi} .
$$

Occasionally, for the near-terminator ionosphere, where the plane parallel approximation breaks down, sec $\chi$ is replaced by the Chapman Function, $C h(x, \chi)$, where $x=R / H_{n}, R$ is the distance from the center of the planet, and $H_{n}$ is the scale height at the peak. The Chapman function has been approximated by various combinations of analytical functions [e.g., Chapman, 1931b; Rishbeth and Garriott, 1969; Bauer, 1973]. Chapman functions are not often used in models because of the ease of computing the column densities for spherical geometry numerically, as described, for example, by Rees [1989].

[13] If the altitude of maximum ionization for overhead Sun is defined as $z=0$, then $n_{0}=\left(\sigma^{a} H\right)^{-1}$, and, expressing $F^{\infty}$ in terms of $q_{\text {max }, 0}^{i}$, the ionization rate as a function of altitude and solar zenith angle is

$$
q_{\chi}^{i}(z)=q_{\max , 0}^{i} \exp \left[1-\frac{z}{H}-\sec \chi e^{-z / H}\right] .
$$

At high altitudes $(z \rightarrow \infty)$ the ionization rate profile follows that of the neutral density, and below the peak $(z \rightarrow-\infty)$, the ionization rate rapidly approaches zero. As the solar zenith angle increases, the peak rises and the magnitude of the maximum ion density decreases.

[14] In a Chapman layer photochemical equilibrium (PCE) prevails, so the production rate of the ion is equal to the loss rate due to dissociative recombination:

$$
q^{i}(z)=\alpha_{\mathrm{dr}} n^{i}(z) n^{e}(z)=\alpha_{\mathrm{dr}}\left[n^{i}(z)\right]^{2},
$$

where the ion density, $n^{i}(z)$, is equal to the electron density, $n^{e}(z)$. The ion or electron density in a Chapman layer is thus given by

$$
\begin{aligned}
n_{\mathrm{i}}(z) & =\left[\frac{q^{i}(z)}{\alpha_{\mathrm{dr}}}\right]^{1 / 2} \\
& =\left[\frac{q_{\max , 0}^{i}}{\alpha_{\mathrm{dr}}}\right]^{1 / 2} \exp \left[\frac{1}{2}-\frac{z}{2 H}-\frac{1}{2} \sec \chi e^{-z / H}\right] .
\end{aligned}
$$

As equation (5) shows, the maximum ion (or electron) density for overhead sun $(\chi=0, z=0)$ is given by

$$
n_{\max , 0}^{i}=\left[\frac{q^{i}(z)_{\max , 0}}{\alpha_{\mathrm{dr}}}\right]^{0.5}
$$

and the maximum ion density for a given solar zenith angle $\chi$ is

$$
n_{\max , \chi}^{i}=n_{\max , 0}^{i}(\cos \chi)^{0.5} .
$$

Equation (5) also indicates that the topside ion scale height should be equal to twice the topside neutral scale height. 

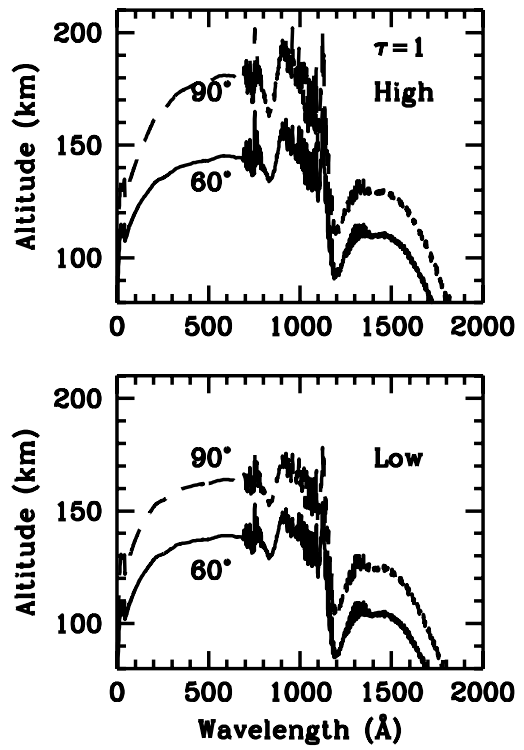

Figure 2. Optical depth unity as a function of wavelength for the interval 0 to $2000 \AA$ for the 60 and $90^{\circ}$ SZA models. (top) High solar activity. (bottom) Low solar activity.

[15] The actual Martian electron density profiles are expected to differ from the idealized Chapman profile for several reasons. Electrons are produced by photoionization of a number of different species over a range of photon wavelengths from the EUV to soft and hard X-ray regions, which reach unit optical depth at different altitudes. The altitudes of optical depth unity for solar zenith angles of 60 and $90^{\circ}$ over the range $0-2000 \AA$ for both the low and high solar solar activity models in the Martian thermosphere are shown in Figure 2. The altitudes of unit optical depth in the $\sim 150-1000 \AA$ range show where the photoabsorption rates should peak.

[16] In addition, the lower thermosphere is not isothermal. The values of $T_{n}$ increase with altitude from the mesopause to the middle thermosphere. The neutral temperatures reach the constant exospheric temperature, $T_{\infty}$, only at high altitudes, which range from $\sim 170$ to $200 \mathrm{~km}$ in our models. $T_{e}$ and $T_{i}$ are equal to the neutral temperature at low altitudes; near the ion peak $T_{e}$ begins to depart from the neutral temperature; $T_{i}$ begins to depart from the neutral temperature near $175 \mathrm{~km}$ [Hanson et al., 1977]. The value of $T_{e}$ increases sharply with altitude near and above the ion peak, and reaches a value of $\sim 1200 \mathrm{~K}$ near $200 \mathrm{~km}$, and $\sim 2000 \mathrm{~K}$ near $230 \mathrm{~km}$ [Rohrbaugh et al., 1979; Chen et al., 1978; Hanson and Mantas, 1988]. The altitude profiles of $T_{n}, T_{i}$, and $T_{e}$ assumed in our model are presented in Figure 3.

[17] The plane parallel approximation begins to break down for solar zenith angles greater than about $60^{\circ}$, which includes all of the MGS profiles from seasons 1, 2, and 4 . Also, photoionization is supplemented by photoelectronimpact ionization. Because the more energetic photons penetrate to lower altitudes, the electron-impact ionization rate usually peaks lower in the ionosphere than does that due to photoionization. In electron-impact ionization, the electrons are slowed down, but not extinguished, as are photons in photoionization. The major ion produced in the Martian ionosphere, $\mathrm{CO}_{2}^{+}$, is mostly transformed by reaction with $\mathrm{O}$ to produce $\mathrm{O}_{2}^{+}$before it can recombine dissociatively. The rate coefficient for dissociative recombination is not a constant, but generally depends on the specific ion and on the value of $T_{e}$. For $\mathrm{O}_{2}^{+}$, the major ion in the Martian ionosphere, our adopted value for $\alpha_{\mathrm{dr}}$ is $1.95 \times$ $10^{-7}\left(300 / T_{e}\right)^{0.7} \mathrm{~cm}^{3} \mathrm{~s}^{-1}$ for $T_{e}<1200 \mathrm{~K}$, and is proportional to $\left(300 / T_{e}\right)^{0.56}$ for $T_{e}>1200 \mathrm{~K}$ [Alge et al., 1983; Mehr and Biondi, 1969]. Finally, the temperatures and number density profiles of the background atmosphere are expected to change with SZA.

[18] Given all these caveats, it would be surprising if real electron density profiles were to closely imitate a Chapman layer. All of these effects mentioned will tend to broaden the peak and change its altitude. To determine the degree to which the observed layers exhibit Chapman-like behavior, the measured peak densities as a function of solar zenith angle have often been fitted to the equation

$$
n_{\max , \chi}^{i}=A(\cos \chi)^{k} \text {, }
$$

which is analogous to equation (7), but where $k$ and $A$ are treated as free parameters. In Chapman theory for a plane parallel atmosphere, $k=0.5$ and $A$ is interpreted as the peak electron density at the subsolar point, $n_{\max , 0}^{i}$, which should be a constant for a given atmospheric model and value of $F^{\infty}$. Equations (2) and (6) show, however, that $n_{\max , 0}^{i}$ contains some "constants" that are actually variable. In addition to $F^{\infty}$ representing a range of photon wavelengths that reach unit optical depth at different altitudes, $\sigma^{i}$ and $\sigma^{a}$ vary with species and wavelength over the range of ionizing photons; the pressure scale height $H$ should be replaced by $H_{n}$, which depends on the neutral temperature and its altitude gradient, the acceleration of gravity, and the average mass $m_{a}$, none of which is constant over the ionospheric layer. At high altitudes, the PCE approximation fails.

[19] Different combinations of radio occultation data sets have been analyzed by several investigators and compared to idealized Chapman layers. Zhang et al. [1990] carried out the most complete analysis of the radio occultation profiles that were available before the MGS mission. Analyses of the variation of electron density profiles with SZA were also made by Hantsch and Bauer [1990].

[20] Other analyses of Martian electron density profiles include that of Bauer and Hantsch [1989], who determined

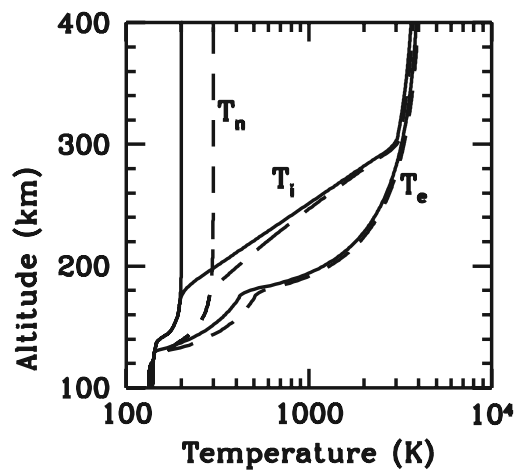

Figure 3. Neutral, ion, and electron temperature profiles assumed in the models. The solid curves are for low solar activity and the dashed curves are for high solar activity. 
the solar activity variation of the neutral and plasma scale heights for the available radio occultation profiles. Mendillo et al. [2003] compared the morphology of the two ionospheric layers on Mars with the contemporaneous terrestrial layers; they showed that the peak densities for the two planets were highly correlated. Martinis et al. [2003] modeled MGS data from March 1999 and showed that the day-to-day variability of the observed $F_{1}$ electron density profiles on Mars closely followed variations in the solar EUV fluxes, as indicated by the $F_{10.7}$ solar EUV proxy. The $E$ peak density was found to exhibit larger variability than could be accounted for by the $F_{10.7}$ index. This is to be expected since the variations of the solar soft X-ray photon fluxes are well known to be larger than those of the EUV fluxes. Rishbeth and Mendillo [2004] carried out same-day comparisons of the peaks of the Martian ionospheric layers, which they named M1 and M2, with the terrestrial $E$ and $F_{1}$ layers measured by six ionosondes for the same period. They found that the morphologies and variabilities of the peaks on the two planets were well correlated. Breus et al. [2004] analyzed 732 electron density profiles in the northern hemisphere, and 219 profiles in the southern hemisphere obtained by the MGS Radio Science experiment. They identified the peak electron density and derived the neutral scale height and the value of $T_{e}$ in the vicinity of the ionization peak for each of the profiles.

[21] We model here the electron density profiles in the Martian ionosphere for solar zenith angles $\chi$ ranging from $60^{\circ}$ to $90^{\circ}$ for both low and high solar activities. We report the altitudes of the peaks in the production rate profiles and in the total ion or electron density profiles. We then fit the model peak densities to equation (8), and derive values of $A$ and $k$ for each SZA interval, and the overall best fit for the SZA range from 60 to $85^{\circ}$. We also compare our values to those we and others have derived from the radio occultation data from MGS and other spacecraft. The neutral and ion density and plasma pressure scale heights in our models, $H_{n}$, $H_{i}$, and $H_{p}$, both near the peak and on the topside, are compared to those derived from the measured electron density profiles and to those appropriate to a Chapman profile. We then compare the low and high solar activity models at comparable solar zenith angles and estimate the variation of the peak densities and the scale heights as a function of $F_{10.7}$.

\section{Models}

[22] Unlike our previous Mars models, we employ here the Solar 2000 v2.22 solar flux models of W. K. Tobiska (private communication, 2003, 2004) without any enhancement in soft X-ray fluxes. For low solar activity, we adopt the v2.22 76200 fluxes, which are characterized by an $F_{10.7}$ of $\sim 68$; for the high solar activity solar fluxes, we adopt the v2.22 99178 fluxes, which are characterized by an $F_{10.7}$ of $\sim 207$. The solar photon fluxes that we use are given at $1 \AA$ intervals in the continuum and as delta functions representing the integrated intensities at the strong solar lines, for a total of 1811 wavelengths from 18 to $2000 \AA$. The S2K v2.2x fluxes are normalized to measurements of the Thermosphere Ionosphere Mesosphere Energetics and Dynamics mission Solar EUV Experiment [e.g., Woods et al., 2000, 2005] and differ significantly from the fluxes from Hinteregger et al.
[1981; see also Torr et al., 1979] and the S2K v1.24 fluxes that we have used recently [Fox, 2004; Fox and Paxton, 2005].

[23] For wavelengths less than $18 \AA$ we have adopted the solar fluxes from Ayres [1997, also private communication, 1996]. These harder X ray solar fluxes are highly variable but are absorbed at altitudes below about $100 \mathrm{~km}$, which is outside the region of interest of this model. The effects of variations of hard $\mathrm{X}$ rays will treated in another publication.

[24] We have constructed models for solar zenith angles of $60,65,70,75,80,85$, and $90^{\circ}$. We include photoionization, electron-impact ionization, electron-impact excitation, and, for molecules, photodissociation, photodissociative ionization, electron-impact dissociation, and electron-impact dissociative ionization. The range of primary and steady state photoelectron fluxes included is $0-600 \mathrm{eV}$ distributed in $1 \mathrm{eV}$ bins.

[25] Our model is a one-dimensional steady state model in which we include molecular and eddy diffusion for the neutrals and ambipolar diffusion for the ions. The rotation of Mars is included only in computing the value of the effective acceleration of gravity. We compute here altitude density profiles for 14 ions, $\mathrm{CO}_{2}^{+}, \mathrm{Ar}^{+}, \mathrm{N}_{2}^{+}, \mathrm{O}^{+}\left({ }^{4} S\right), \mathrm{O}^{+}\left({ }^{2} D\right)$, $\mathrm{O}^{+}\left({ }^{2} P\right), \mathrm{CO}^{+}, \mathrm{C}^{+}, \mathrm{N}^{+}, \mathrm{NO}^{+}, \mathrm{O}_{2}^{+}, \mathrm{O}^{++}, \mathrm{He}^{+}, \mathrm{H}^{+}$, and nine neutral species, including $\mathrm{NO}, \mathrm{N}\left({ }^{4} S\right), \mathrm{N}\left({ }^{2} D\right), \mathrm{N}\left({ }^{2} P\right), \mathrm{C}, \mathrm{H}$, $\mathrm{H}_{2}, \mathrm{O}\left({ }^{1} D\right)$, and $\mathrm{O}\left({ }^{1} S\right)$. Our background neutral density profiles for the low and high solar activity models are nearly the same as those we have presented previously [Fox, 2004]. The neutral models consist of altitude profiles of 12 species, including $\mathrm{CO}_{2}, \mathrm{Ar}, \mathrm{N}_{2}, \mathrm{O}, \mathrm{O}_{2}, \mathrm{NO}, \mathrm{CO}, \mathrm{C}, \mathrm{N}$, $\mathrm{H}, \mathrm{H}_{2}$, and $\mathrm{He}$, with densities over the altitude range $80-$ $400 \mathrm{~km}$ given in $1 \mathrm{~km}$ intervals. In order to compute the local photon fluxes, however, we have extended the background model to $700 \mathrm{~km}$. The major background species for our low solar activity models are based on the Viking 1 measured densities [e.g., Nier and McElroy, 1976, 1977], and the high solar activity model is based on the Mars Thermospheric General Circulation Model (MTGCM) of Bougher et al. [2000, private communication, 2001] that is appropriate to $60^{\circ} \mathrm{SZA}$. In the high solar activity model, we have multiplied the $\mathrm{O}$ number densities by 2 so that the mixing ratios are larger than those in the low solar activity model. The resulting $\mathrm{O}$ mixing ratios at $130 \mathrm{~km}$ are $2 \%$ in the low solar activity model, and $3.2 \%$ in the high solar activity model. The $\mathrm{O}$ mixing ratios in the Venus thermosphere have been shown in various models to vary greatly with solar activity [e.g., Fox and Bougher, 1991]. Bougher et al. [2000] have argued, however, that the $\mathrm{O}$ mixing ratio variations over a solar cycle in the Martian thermosphere are limited by dynamical processes, which include large-scale winds and eddy diffusion. There are no in situ measurements of the Martian thermospheric $\mathrm{O}$ mixing ratio either at low or high solar activity. O mixing ratios for Viking conditions have been derived from the $\mathrm{CO}_{2}^{+} / \mathrm{O}_{2}^{+}$ratio as $1-2 \%$ at $130 \mathrm{~km}$ [e.g., Hanson et al., 1977; Fox and Dalgarno, 1979]. Stewart et al. [1992] have derived smaller global $\mathrm{O}$ mixing ratios of $\sim 0.7 \%$ from remote sensing of $1304 \AA$ emission intensities from the UV spectrometer on the Mariner 9 orbiter.

[26] We assume here that the background atmosphere is constant with solar zenith angle, except for those minor constituents that we calculate self-consistently in the model, 


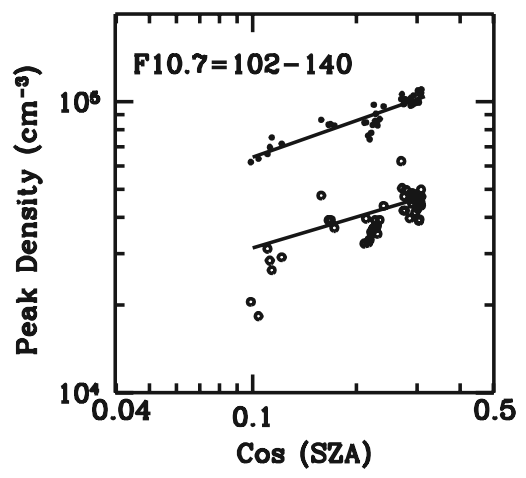

Figure 4. Densities of the $E$ and $F_{1}$ peaks as a function of solar zenith angle from the MGS radio occultation data for seasons 1,2 , and 4 , and for $F_{10.7}$ range 102-140. One profile was chosen for each day of data, which represents that for the median $F_{1}$ peak density. The filled circles are the $F_{1}$ peaks and the open circles are for the $E$ peaks. The points were fitted by linear least squares regressions, the best fit values of $n_{\text {max }, 0}$ and $k$ in equations (7) and (8) were $1.68 \times$ $10^{5} \mathrm{~cm}^{-3}$ and 0.42 , respectively, for the $F_{1}$ peak, and $8.9 \times$ $10^{4} \mathrm{~cm}^{-3}$ and 0.55 , respectively, for the $E$ peak. Since the peak densities are not well distributed in longitude, the standard deviations were not included, and limited validity should be assigned to the derived parameters.

including $\mathrm{N}, \mathrm{NO}, \mathrm{C}, \mathrm{H}$, and $\mathrm{H}_{2}$. For $\mathrm{H}$ and $\mathrm{H}_{2}$, we do not carry out full photochemical calculations. $\mathrm{H}$ is assumed to be produced in photodissociation and photodissociative ionization of $\mathrm{H}_{2}$ and also has chemical sources and sinks in our model [e.g., Fox and Sung, 2001; Fox, 2003, 2004]. Because the chemistry of $\mathrm{H}$ is not complete, however, we fix the densities at the lower boundaries at $80 \mathrm{~km}$ so that $\mathrm{H}$ densities at $250 \mathrm{~km}$ in the high solar activity model are in the range $(2-4) \times 10^{4} \mathrm{~cm}^{-3}$, in agreement with the Lyman alpha airglow measured by Mariners 6, 7 and 9 [e.g., Anderson and Hord, 1971; Anderson, 1974]. At low solar activity, the $\mathrm{H}$ density in the same altitude range is an order of magnitude or more larger, owing to the smaller escape rate [e.g., Levine et al., 1978; Krasnopolsky, 2002]. $\mathrm{H}_{2}$ is assumed to be characterized by a mixing ratio of $10 \mathrm{ppm}$ at the lower boundary of the model. This value is within the range $(15 \pm 5) \mathrm{ppm}$ derived by Krasnopolsky and Feldman [2001; see also Krasnopolsky, 2002] from FUSE observations of the Lyman bands of $\mathrm{H}_{2}$. The upper boundary conditions for $\mathrm{H}$ and $\mathrm{H}_{2}$ are the Jeans velocities reduced by a factor of about 0.5 to account for the depletion of the high energy tail of the energy distribution [e.g., Shizgal and Blackmore, 1986; Pierrard, 2003].

[27] $\mathrm{N}$ and NO are sources of odd nitrogen to the lower atmosphere, and therefore we impose downward fluxes for those species at the lower boundary of the model. Since we do not model the middle atmosphere, we make no attempt to determine accurately the magnitudes of the $\mathrm{N}$ and $\mathrm{NO}$ fluxes, except that we impose the condition that the fluxes must be small enough so that the densities do not become negative at the lower boundary. The downward fluxes assumed for $\mathrm{NO}$ are in the ranges $(1-2.5) \times 10^{7} \mathrm{~cm}^{-2}$ $\mathrm{s}^{-1}$, and (4-7) $\times 10^{7} \mathrm{~cm}^{-2} \mathrm{~s}^{-1}$, for the low and high solar activity models, respectively. The downward flux of $\mathrm{N}$ is assumed to be $100 \mathrm{~cm}^{-2} \mathrm{~s}^{-1}$, except for the low solar activ- ity model at $90^{\circ} \mathrm{SZA}$, where it is reduced to $10 \mathrm{~cm}^{-2} \mathrm{~s}^{-1}$. We assume a zero flux lower boundary condition for C, and fixed density lower boundary conditions for $\mathrm{N}\left({ }^{2} D\right)$, $\mathrm{N}\left({ }^{2} P\right), \mathrm{O}\left({ }^{1} D\right)$, and $\mathrm{O}\left({ }^{1} S\right)$. Zero-flux upper boundary conditions are assumed for the computed neutral species other than $\mathrm{H}$ and $\mathrm{H}_{2}$.

[28] For the ions, fixed density lower boundary conditions and upward velocity upper boundary conditions of $1 \times$ $10^{5} \mathrm{~cm} \mathrm{~s}^{-1}$, and $1.2 \times 10^{5} \mathrm{~cm} \mathrm{~s}^{-1}$ are imposed for low and high solar activities, respectively. The low solar activity upward velocity is that which is found to necessary to reproduce the Viking $1 \mathrm{O}_{2}^{+}$profile [e.g., Chen et al., 1978; Fox, 1993, 1997, 2004; Hanson et al., 1977]. The high solar activity value is roughly that which was required to fit the ratio of the electron density at the peak, $\sim 1.8 \times 10^{5} \mathrm{~cm}^{-3}$, to that at $300 \mathrm{~km}$, about $\sim 7 \times 10^{3} \mathrm{~cm}^{-3}$, from the Mariner 6 profile [Fjeldbo et al., 1970]. Upward velocity boundary conditions probably represent upward fluxes at low altitudes and horizontal ion flows at high altitudes. Shinagawa and Cravens [1989] have suggested that an upward flux at the top of a one-dimensional model probably represents the divergence of the horizontal flux of ions, which may be related to the interaction between the solar wind and the ionosphere [e.g., Ma et al., 2004; Lundin et al., 2006]. The imposition of upward velocity boundary conditions affects only the topside scale height, but has little to no effect on the $F_{1}$ and $E$ peak densities.

[29] While the assumption that background density profiles of the main neutral species do not change with solar zenith angle almost certainly introduces some errors, a comparison of our models with the MGS data and other radio occultation data provides a measure of the accuracy of this assumption.

\section{Data Analysis}

[30] We have analyzed the MGS radio occultation profiles for seasons 1,2, and 4, which are all in the northern hemisphere and thus relatively free of the effects of crustal magnetic fields, which are more common in the southern hemisphere. We do not include magnetic fields in our model.

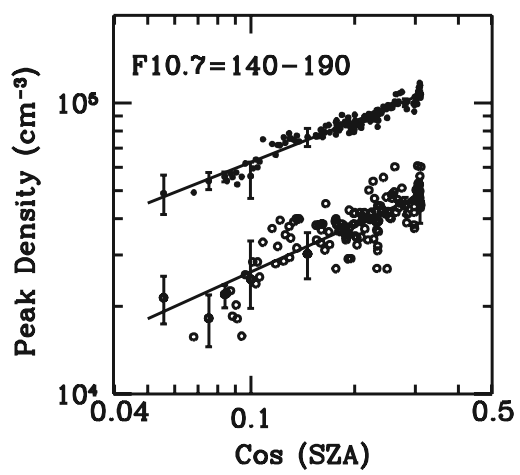

Figure 5. Similar to Figure 4, except for the $F_{10.7}$ range 140-190, which contains 141 points that are well distributed over longitude. Standard deviations are included in the analysis of this data set. The derived values of $n_{\max , 0}^{i}$ and $k$ from Equations (7) and (8) are $(1.82 \pm 0.03) \times 10^{5} \mathrm{~cm}^{-3}$ and $0.465 \pm 0.010$, respectively, for the $F_{1}$ peak, and $(9.4 \pm 0.4)$ $\times 10^{4} \mathrm{~cm}^{-3}$ and $0.551 \pm 0.024$, respectively, for the $E$ peak. 


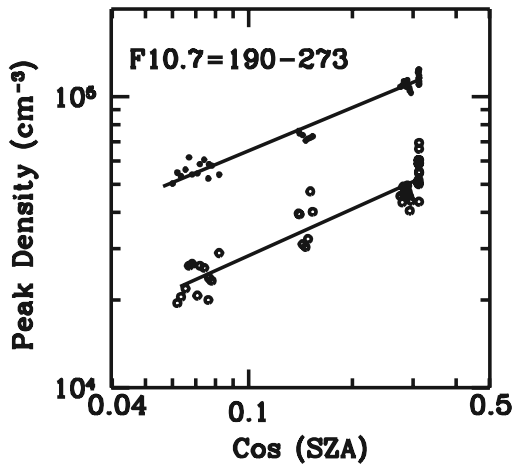

Figure 6. Same as Figure 4, but for $F_{10.7}$ values in the range 190 to 273 . The best fit values of $n_{\max , 0}^{i}$ and $k$ in equations (7) and (8) were $2.0 \times 10^{5} \mathrm{~cm}^{-3}$ and 0.49 , respectively, for the $F_{1}$ peak, and $9.6 \times 10^{4} \mathrm{~cm}^{-3}$ and 0.53 , respectively, for the $E$ peak. As for the $F_{10.7}$ range for Figure 4, the densities are not well distributed in longitude, so the standard deviations were not included in the data analysis, and limited validity should be assigned to the derived parameters.

For each day, we analyze one profile which exhibits the median $F_{1}$ peak for the day. The dates for the above seasons are 24-31 December 1998, 9-27 March 1999, and 1 November 2000 to 6 June 2001, respectively. The SZA assigned to each radio occultation profile is that at $130 \mathrm{~km}$, and the atmosphere sampled over the profile is within $6^{\circ}$ or so of the nominal SZA (D. Hinson, private communication, 2006). The solar zenith angle range for these seasons is $\sim 71-87^{\circ}$.

[31] We have divided the data into three solar activity bins. The range of $F_{10.7}$ for bins 1,2 and 3 are 102-140, 140-190, and 190-273, respectively. The value of $F_{10.7}$ at Mars was adjusted to the orbital position of Mars with respect to that of Earth and to account for the actual SunMars distance compared to that of the mean distance. The $\operatorname{logs}$ of the $E$ and $F_{1}$ peak densities as a function of $\log$ $(\cos \chi)$ are shown in Figures 4, 5, and 6, for bins 1, 2, and 3, respectively. The data points were fitted by a linear least squares regression. The values of the slopes $k$ and the intercepts $A$, from equation (8) were derived from these fits. For $F_{10.7}$ bins 1 and 3, exponents $k$ of 0.42 and 0.49 , respectively, were derived for the $F_{1}$ peaks, and the predicted subsolar peak densities were $1.68 \times 10^{5}$ and $2.0 \times$ $10^{5} \mathrm{~cm}^{-3}$, respectively. We note, however, that the first and third bins contained only a few profiles, which are not welldistributed in longitude, and thus the characteristics derived from these data have limited validity. Thus we do not include the standard deviations of the peak densities for these bins. For bin 2, which contains 141 data points, we have included the standard deviations in deriving the characteristics of the linear fits. The standard deviations for seven representative data points are included in Figure 5. The error bars appear large for small peak magnitudes, but for the densities that approach $\sim 10^{5} \mathrm{~cm}^{-3}$, the error bars are barely visible on the plots, which are logarithmic. The derived value of $k$ is $0.465 \pm 0.010$ and the value of $A$ is $(1.82 \pm 0.03) \times 10^{5} \mathrm{~cm}^{-3}$ for the $F_{1}$ peaks. The median values of the $F_{1}$ peak densities for $F_{10.7}$ bins 1,2 , and 3 , are $9.74 \times 10^{4}, 8.70 \times 10^{4}$, and $1.08 \times 10^{5} \mathrm{~cm}^{-3}$, respectively.
[32] We also analyzed the lower $E$ peaks. Locating the altitude and magnitude of the lower peak was found to be difficult when it was observed as only as a shoulder, so these quantities were determined by visual inspection of the profiles. Although this procedure obviously limits the accuracy of both the peak densities and altitudes somewhat, we concluded that it was better than attempting to identify an inflection point in inherently noisy data. For the lower peak or shoulder, slopes $k$ of 0.55 and 0.53 and intercepts $A$ of $8.9 \times 10^{4}$ and $9.6 \times 10^{4} \mathrm{~cm}^{-3}$, were determined for bins 1 and 3 , respectively. For bin 2, we have included the standard deviations of the peak magnitudes and derive a slope of $0.551 \pm 0.024$ and an intercept of $(9.4 \pm 0.4) \times 10^{4} \mathrm{~cm}^{-3}$. The median values for the $E$-peak densities are $4.1 \times 10^{4}$, $3.9 \times 10^{4}$, and $4.5 \times 10^{4} \mathrm{~cm}^{-3}$, for bins 1,2 , and 3 , respectively. With the addition of the fifth, sixth, and seventh occultation seasons, more profiles should be added, and the parameters will be more accurately determined.

\section{Model Results}

\subsection{Peak Altitudes}

[33] Altitude profiles of the predicted photoionization rates, electron-impact ionization rates, total production rates of ions, and peak densities for a range of solar zenith angles for low and high solar activities are shown in Figures 6 to 9. The altitude range of 80 to $220 \mathrm{~km}$ was chosen for presentation because it is approximately that for which the MGS RS electron densities have been reported. There are seven curves on each figure, which are, in order of decreasing peak density and increasing peak height, those appropriate to solar zenith angles of $60,65,70,75,80,85$, and $90^{\circ}$. The altitudes of peak production and peak electron densities for all the models for the $F_{1}$ and $E$ regions are summarized in Tables 1 and 2, respectively.

[34] The computed photoionization rates as a function of altitude and solar zenith angle are shown in Figure 7. For the low solar activity models, the profiles exhibit an upper peak that rises from 134 to $149 \mathrm{~km}$, and a lower peak that rises from 109.5 to $123.5 \mathrm{~km}$ as the SZA increases from 60 to $85^{\circ}$. For the high solar activity models, the photoionization rate profiles exhibit an upper peak that rises from 136 to

Table 1. Predicted Altitudes of the $F_{1}$ Peak Ion Densities and Production Rates as a Function of Solar Zenith Angle (SZA), km

\begin{tabular}{|c|c|c|c|c|}
\hline$\underline{\mathrm{SZA}}$ & Ion Density & $\begin{array}{c}\text { Photo } \\
\text { Production }\end{array}$ & $\begin{array}{c}\text { Electron Impact } \\
\text { Production }\end{array}$ & $\begin{array}{c}\text { Total } \\
\text { Production }\end{array}$ \\
\hline \multicolumn{5}{|c|}{ Low Solar Activity } \\
\hline $60^{\circ}$ & 136 & 134 & 127 & 133 \\
\hline $65^{\circ}$ & 137 & 136 & 128 & 134 \\
\hline $70^{\circ}$ & 139 & 138 & 130 & 136 \\
\hline $75^{\circ}$ & 141 & 140 & 133 & 138 \\
\hline $80^{\circ}$ & 144 & 144 & 136 & 142 \\
\hline $85^{\circ}$ & 149 & 149 & 141 & 148 \\
\hline $90^{\circ}$ & 157 & 159 & 150 & 157 \\
\hline \multicolumn{5}{|c|}{ High Solar Activity } \\
\hline $60^{\circ}$ & 137 & 136 & 129 & 135 \\
\hline $65^{\circ}$ & 138 & 138 & 132 & 136 \\
\hline $70^{\circ}$ & 142 & 139 & 132 & 138 \\
\hline $75^{\circ}$ & 144 & 143 & 135 & 142 \\
\hline $80^{\circ}$ & 148 & 148 & 137 & 145 \\
\hline $85^{\circ}$ & 158 & 158 & 143 & 154 \\
\hline $90^{\circ}$ & 178 & 171 & 158 & 165 \\
\hline
\end{tabular}


Table 2. Predicted Altitudes of the $E$-Region Peak Densities and Ion Production Rates as a Function of Solar Zenith Angle, km

\begin{tabular}{|c|c|c|c|c|}
\hline SZA & Ion Density & $\begin{array}{c}\text { Photo } \\
\text { Production }\end{array}$ & $\begin{array}{c}\text { Electron Impact } \\
\text { Production }\end{array}$ & $\begin{array}{c}\text { Total } \\
\text { Production }\end{array}$ \\
\hline \multicolumn{5}{|c|}{ Low Solar Activity } \\
\hline $60^{\circ}$ & 110 & 109.5 & 109 & 110 \\
\hline $65^{\circ}$ & 111 & 110.5 & 111 & 111 \\
\hline $70^{\circ}$ & 113 & 111.5 & 111 & 113 \\
\hline $75^{\circ}$ & 115 & 114.5 & 114 & 115 \\
\hline $80^{\circ}$ & 117.5 & 116.5 & 117 & 118 \\
\hline $85^{\circ}$ & 123.5 & 123.5 & 122 & 123.5 \\
\hline $90^{\circ}$ & 130.5 & 129.5 & 130 & 131.5 \\
\hline \multicolumn{5}{|c|}{ High Solar Activity } \\
\hline $60^{\circ}$ & 115 & 114 & 114 & 114.5 \\
\hline $65^{\circ}$ & 116 & 117.5 & 115 & 116 \\
\hline $70^{\circ}$ & 117 & 117.5 & 117 & 117 \\
\hline $75^{\circ}$ & 119 & 119.5 & 118 & 119.5 \\
\hline $80^{\circ}$ & 122 & 121.5 & 121 & 121 \\
\hline $85^{\circ}$ & 128 & 126.5 & 125 & 125 \\
\hline $90^{\circ}$ & 136.5 & 136 & 133 & 133 \\
\hline
\end{tabular}

$158 \mathrm{~km}$, and a lower peak that rises from 114 to $126.5 \mathrm{~km}$ as the SZA increases over the same range. A large increase is observed in the altitudes of peak photoionization between the solar zenith angles of 85 and $90^{\circ}$ for both models. At high altitudes the photoproduction rate profiles merge together, as would be expected as the optical depth approaches zero. In the models, we identify the altitude of a lower shoulder in the production rate and density profiles as that for which the differences between the values at adjacent altitudes is a minimum. Thus because our altitude increment is $1 \mathrm{~km}$, the altitude of the shoulder may be expressed as located at the nearest half kilometer, but high accuracy is not assigned to these values.

[35] Computed altitude profiles of the production rates from electron-impact ionization are shown in Figure 8 and those for the total ionization rates are shown in Figure 9. The electron impact production rate profiles exhibit two peaks that are comparable in magnitude. The upper peaks in the photoelectron impact ionization profile are below those of the photoproduction rate peaks by $6-13 \mathrm{~km}$. Photoionization dominates the ion production for the $F_{1}$ peak, and the upper peaks in the total production rate profiles are found to be slightly below those for photoionization. For the $E$ peak, impact of photoelectrons and secondary electrons dominates and the altitude of total production is near that for electron impact. The computed electron density profiles for low and high solar activity models as a function of SZA are shown in Figure 10.

[36] The model $F_{1}$ peak rises from 136 to $149 \mathrm{~km}$ at low solar activity, and from 137 to $158 \mathrm{~km}$ at high solar activity, as the solar zenith angle increases from 60 to $85^{\circ}$. The largest increases in the $F_{1}$ peak altitudes are from 85 to $90^{\circ}$ SZA, where the peak is predicted to rise by $8-20 \mathrm{~km}$. The $F_{1}$ peak densities are found to occur slightly above the altitudes of peak production process for the following reasons. As mentioned previously, the dissociative recombination rate coefficient of the major ion $\mathrm{O}_{2}^{+}$has a negative electron temperature dependence. In the $F$-region, $T_{e}$ increases significantly with altitude (cf., Figure 3), and therefore the $\mathrm{O}_{2}^{+}$loss rates decrease with altitude. Thus the electron densities are larger and the peaks are higher than those that would be expected for an altitude-independent $T_{e}$ profile. This is especially true for the high solar activity $90^{\circ}$ SZA peak, which appears $13 \mathrm{~km}$ above the total production peak. Figure 9 shows that there is a shoulder near $168.5 \mathrm{~km}$, which is associated with the peak production rates. Owing to the rapid rise of $T_{e}$ in this region, however, the absolute maximum appears near $178 \mathrm{~km}$. We note also that the $\mathrm{O}_{2}^{+} \mathrm{PCE}$ boundary for the high solar activity $90^{\circ} \mathrm{SZA}$ model is near $160 \mathrm{~km}$, so the predicted $F_{1}$ peak is above the PCE region. For the other models, the $\mathrm{O}_{2}^{+}$PCE boundary varies from $\sim 170 \mathrm{~km}$ for the $90^{\circ} \mathrm{SZA}$ low solar activity model to $\sim 180 \mathrm{~km}$ for both high and low solar activity $60^{\circ}$ SZA models.

[37] The predicted altitude of the $E$ electron density peak or shoulder rises over the SZA range of 60 to $85^{\circ}$ from 110 to $123 \mathrm{~km}$ in the low solar activity model and from 115 to $128 \mathrm{~km}$ in the high solar activity model. The predicted increase in the $E$ peak altitude from 85 to $90^{\circ} \mathrm{SZA}$ is in the range $7-9 \mathrm{~km}$.

[38] It is difficult to compare the altitudes of the model peaks with the radio occultation data. The data from Mariners 4, 6, and 7, Vikings 1 and 2, and the Mariner 9 extended mission showed $F_{1}$ peak densities at lower altitudes, in the range $\sim 120-150 \mathrm{~km}$ for the SZA range from 60 to $85^{\circ}$ [e.g., Zhang et al., 1990]. Our analysis of the MGS data from seasons 1,2, and 4 showed that the $F_{1}$ peak altitudes vary from 125 to $148 \mathrm{~km}$ over the SZA range 71$87^{\circ}$. By contrast, the $F_{1}$ peaks for the 70 to $85^{\circ} \mathrm{SZA}$ models increase from 139 to $149 \mathrm{~km}$ at low solar activity and from 142 to $158 \mathrm{~km}$ at high solar activity.

[39] At $90^{\circ} \mathrm{SZA}$, our model $F_{1}$ electron density peaks are at 157 and $178 \mathrm{~km}$, for low and high solar activity,
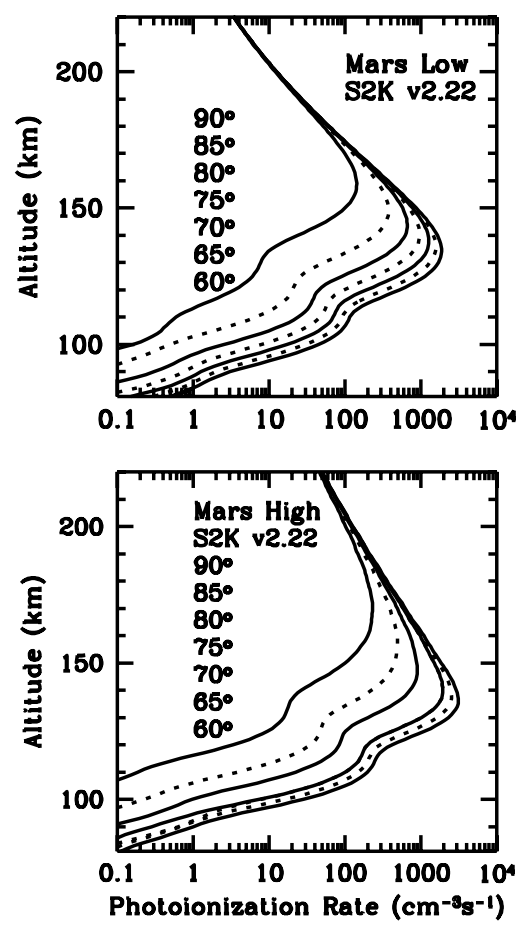

Figure 7. Altitude profiles of the photoionization rates for all the models. The curves are, in order of decreasing peak photoionization rate and increasing peak altitude, those for the $60,65,70,75,80,85$, and $90^{\circ}$ models. (top) Low solar activity. (bottom) High solar activity. 

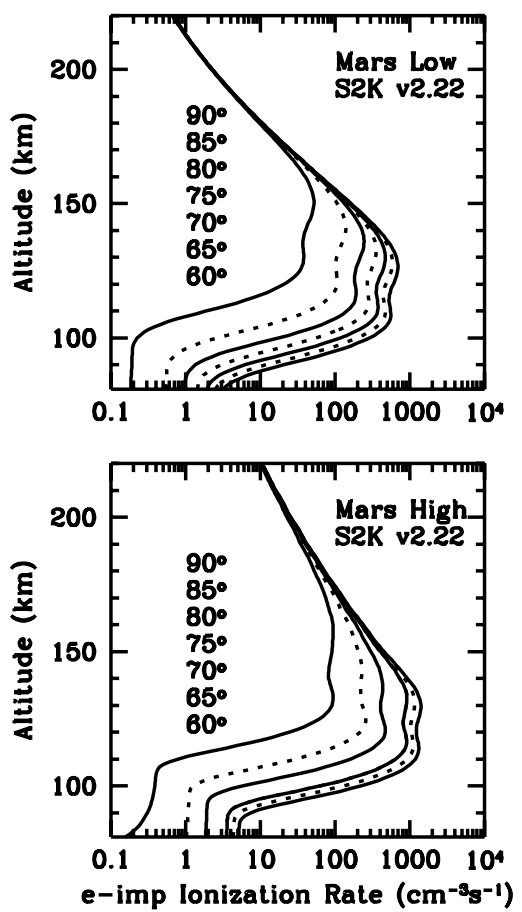

Figure 8. Altitude profiles of the electron impact ionization rates for all the models. The ionization rates include those produced by photoelectrons, and those produced by secondary and subsequent electrons. The curves are, in order of decreasing peak production rate and increasing peak altitude, those for the $60,65,70,75,80,85$, and $90^{\circ}$ models. (top) Low solar activity. (bottom) High solar activity.

respectively. There are very few electron density profiles for solar zenith angles near $90^{\circ}$ to compare to our models. A few RO profiles from the Viking 2 orbiter were in the range 89-94 [Zhang et al., 1990]. These orbits were at low solar activity. They show that the range of peak altitudes are similar to our predictions, about $150-180 \mathrm{~km}$. A large increase in the peak altitudes to values in the 180 to $200 \mathrm{~km}$ range seems to occur for solar zenith angles greater than $93^{\circ}$. Four Mariner 9 ingress profiles exhibited solar zenith angles in the range $89-100^{\circ}$. The peak densities, however, also appear to be in the $150-180 \mathrm{~km}$ range. The error incurred by assuming spherical symmetry in retrieving radio occultation electron density profiles should maximize near $90^{\circ} \mathrm{SZA}$, but the impact on the profiles is difficult to ascertain. A selected profile from the MARSIS instrument on MEX for an SZA of $89.3^{\circ}$, however, showed a peak at $195 \mathrm{~km}$ [Gurnett et al., 2005], which is significantly higher than our $90^{\circ}$ SZA model peaks.

[40] Since the heights of the measured peaks are determined by many factors other than photochemistry, the higher peaks in the MGS data do not necessarily correspond to larger solar zenith angles. Our models do not include the strong longitudinal variation of peak height, which results from wave activity or dust loading in the lower atmosphere.

[41] Bougher et al. [2001] found that for the first MGS occultation season, where the solar zenith angle range was 79 to $81^{\circ}$, the average $F_{1}$ peak height was $134.4 \mathrm{~km}$, and the lower peak was found in the altitude range $110-115 \mathrm{~km}$. Solar activity for this occultation season was moderate, with an $F_{10.7}$ value ranging from $\sim 130$ to 170 . Bougher et al. [2004] analyzed the first five data sets, and reported a mean $F_{1}$ peak height in the range $\sim 133.5-135 \mathrm{~km}$ for solar zenith angles from $78-82^{\circ}$. By contrast, the $80^{\circ} \mathrm{SZA}$ model $F_{1}$ peak altitudes appear in the range $144-148 \mathrm{~km}$, and the $E$ peak altitudes appear in the range $117-122 \mathrm{~km}$, where the lower value is for low solar activity and the higher value is for high solar activity.

[42] The Mariner 9 radio occultation measurements at orbital insertion occurred during a planetwide dust storm, and the altitudes of the peaks were found to be in the range 135 to $155 \mathrm{~km}$ for solar zenith angles of $\sim 50$ to $60^{\circ}$. Our $60^{\circ}$ solar zenith angle models exhibit $F_{1}$ peaks near $136-$ $137 \mathrm{~km}$ for nondusty conditions. Thus it appears that compared to the existing radio science data for solar zenith angles that are less than $85^{\circ}$ and nondusty conditions, our model peak altitudes are too high by $\sim 5-10 \mathrm{~km}$.

[43] It is possible that our exospheric temperatures are too large near the terminator, and there may be a small vertical offset for all the models. $\mathrm{O}$ is the major constituent of the models at altitudes above 195 and $209 \mathrm{~km}$ in the low and high solar activity models, respectively. Since we have doubled the $\mathrm{O}$ densities in the high solar activity model, this might be expected to result in somewhat higher electron density peaks. A comparison to our previous model shows that the effect is negligible [Fox, 2004]. It is also possible that the absorption cross sections that we adopted are too large. A review of the absorption cross sections for $\mathrm{CO}_{2}$ and $\mathrm{O}$ has not, however, revealed any significant uncertainties. Small differences from other recent models may arise because our models contain 12 absorbing species, rather
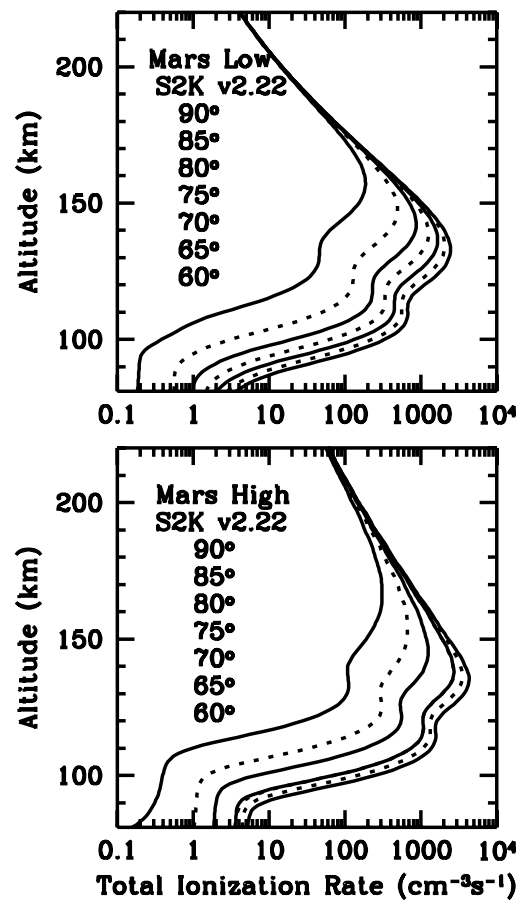

Figure 9. Altitude profiles of the total ionization rates for all the models. The curves are, in order of decreasing peak production rate and increasing peak altitude, those for the $60,65,70,75,80,85$, and $90^{\circ}$ models. (top) Low solar activity. (bottom) High solar activity. 

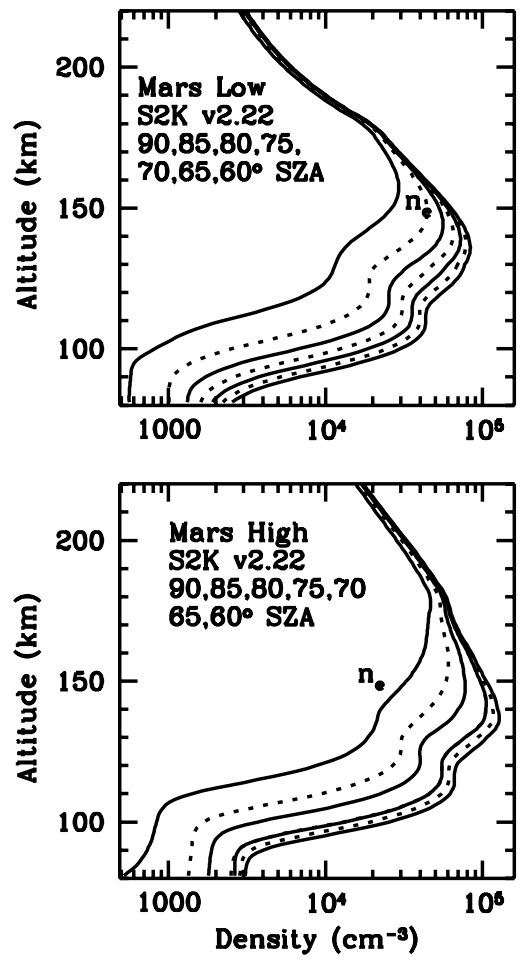

Figure 10. Altitude profiles of the total electron densities for all the models. The curves are, in order of decreasing peak density and increasing peak altitude, those for the 60 , $65,70,75,80,85$, and $90^{\circ}$ models. (top) Low solar activity. (bottom) High solar activity.

than only 2 to 6 species, and our upper altitude for computing the photoabsorption rate is $700 \mathrm{~km}$. Because the altitudes of the peaks do appear to increase as the solar zenith angle increases, as measured by the pre-MGS radio occultation experiments [e.g., Zhang et al., 1990; Hantsch and Bauer, 1990], the MGS data [cf. Breus et al., 2004], and the recent MARSIS data [Gurnett et al., 2005], it appears that the slant column densities for unit optical depth do occur at higher altitudes as the SZA increases, but not as high as our SZA invariant model.

[44] By contrast, we note that radio occultation profiles measured by the Pioneer Venus (PV) Orbiter Radio Occultation (ORO) experiment show that the altitude of the main electron density peak in the Venus ionosphere remains approximately constant at about $140 \mathrm{~km}$ as the solar zenith angle increases from $\sim 20$ to $85^{\circ}$ [Cravens et al., 1981]. This non-Chapman behavior has been ascribed to the collapse of the thermosphere as the daytime thermosphere merges into the nighttime cryosphere. (The magnitudes of the Venusian electron density peaks as a function of solar zenith angle were found, however, to be approximately Chapman-like.)

[45] Thus the Martian thermosphere does not appear to "collapse" with increasing SZA, as does that of Venus. That the altitudes of the model peaks are higher than those of the MGS RS profiles, however, indicates that the assumption of a constant background atmosphere is not justified. There are probably some decreases in the thermospheric temperatures and the neutral densities as the solar zenith angle increases. In particular, the MTGCM shows that there appear to be large changes in the neutral atmosphere for solar zenith angles near $90^{\circ}$ compared to those for smaller solar zenith angles (S. Bougher, private communication, 2006).

[46] Breus et al. [1998] constructed a model in which the diurnal variations of the Martian exospheric temperatures were chosen to approximate the diurnal variations in an early MTGCM of Bougher et al. [1990]. For high solar activity $\left(F_{10.7}=200\right)$, the exospheric temperatures decreased from $\sim 320$ to $260 \mathrm{~K}$ as the local time in the model changed from 1600 to 2000 hours. For low solar activity $\left(F_{10.7}=70\right)$, the exospheric temperature decreased from $\sim 200$ to $160 \mathrm{~K}$ over the same local time period. By fitting the electron density profiles with Chapman functions, Breus et al. [2004] found that $H_{n}$ at the ion peak varied from about 6 to $15 \mathrm{~km}$, but the variability was not strongly correlated with SZA. They found that $H_{n}$ decreased by only $0.12 \mathrm{~km} /$ degree over the SZA range 75 to $87^{\circ}$, and suggested that the variation of the atmosphere near the peak was less than that above the peak.

[47] The predicted maximum total ion densities, neutral and electron temperatures, and neutral scale heights at the peaks of the electron density profiles in the $F_{1}$ and $E$ models are shown in Tables 3 and 4, respectively. The neutral scale heights were calculated numerically from the model densities and are not equal to the pressure scale heights, which are computed as $k T /\left(m_{a} g\right)$.

[48] Table 3 shows that the model neutral scale height at the $F_{1}$ peak increases from 9.0 to $9.8 \mathrm{~km}$ in the low solar activity model, as the solar zenith angle increases from 60 to $85^{\circ}$ SZA. The values of $H_{n}$ for the low solar activity $F_{1}$ peak are in substantial agreement with that determined from Viking electron density profile by Bauer and Hantsch [1989] of $9.5 \mathrm{~km}$ for a solar zenith angle of $45^{\circ}$, and of $10 \mathrm{~km}$ by Hantsch and Bauer [1990] for a selection of preMGS data. The model high solar activity neutral scale heights at the peaks are in the range $8-15.2 \mathrm{~km}$ and increase with increasing SZA. A scale height of $11 \mathrm{~km}$ was derived from the Mariner 6 data by Bauer and Hantsch [1989]. The Mariner 6 ingress electron density profile corresponds, however, to a smaller solar zenith angle of $56-57^{\circ}$. The scale heights in our $60^{\circ}$ SZA models range from 8 to $9 \mathrm{~km}$. We find that the neutral scale height at the $F_{1}$ peak increases only slowly with SZA for values less than about $80^{\circ}$, in qualitative agreement with Breus et al. [2004].

[49] Table 4 shows that for the low solar activity model at the $E$ peak, the scale height ranges from 7.2 to $8.7 \mathrm{~km}$ for the SZA range of 60 to $90^{\circ}$; similarly, for the high solar activity model, the value of $H_{n}$ at the peak varies between 7.1 and $8.0 \mathrm{~km}$.

[50] We note here that there are inherent uncertainties in determining $H_{n}$ by fitting the radio occultation electron density peak profiles to a Chapman layer peak (equation (5)), as has been done by Bauer and Hantsch [1989] and by Breus et al. [1998, 2004]. As mentioned previously, and as Figure 2 shows, ionization is produced by photons characterized by a large range of wavelengths that reach unit optical depth at different altitudes. In addition, ionization is also produced by impact of photoelectrons and secondary electrons, which tend to deposit their energy below that of photons, as shown in Tables 1 and 2. The thermosphere is not isothermal. The effect of the $T_{e}$ dependence of the dissociative recombination rate tends to cause the peak 
Table 3. Characteristics of Model Electron Density $F_{1}$ Peaks for Low and High Solar Activities

\begin{tabular}{|c|c|c|c|c|c|c|}
\hline SZA & Maximum Density, $\mathrm{cm}^{-3}$ & Predicted $k$ & Predicted $n_{\max , 0}^{e}, \mathrm{~cm}^{-3}$ & $T_{n}, \mathrm{~K}$ & $T_{e}, \mathrm{~K}$ & Scale Height km \\
\hline \multicolumn{7}{|c|}{ Low Solar Activity } \\
\hline $0^{\circ}$ & $1.11(5)^{\mathrm{a}}$ & 0.45 & - & 141 & 141 & 8.2 \\
\hline $60^{\circ}$ & $8.3(4)$ & 0.38 & $1.08(5)$ & 145 & 192 & 9.0 \\
\hline $65^{\circ}$ & $7.8(4)$ & 0.38 & $1.08(5)$ & 146 & 200 & 9.1 \\
\hline $70^{\circ}$ & $7.2(4)$ & 0.38 & $1.09(5)$ & 152 & 214 & 9.2 \\
\hline $75^{\circ}$ & $6.5(4)$ & 0.38 & $1.08(5)$ & 156 & 229 & 9.3 \\
\hline $80^{\circ}$ & $5.6(4)$ & 0.34 & $1.00(5)$ & 168 & 250 & 9.5 \\
\hline $85^{\circ}$ & 4.4(4) & - & - & 179 & 283 & 9.8 \\
\hline $90^{\circ}$ & $2.9(4)$ & - & - & 189 & 331 & 10.3 \\
\hline \multicolumn{7}{|c|}{ High Solar Activity } \\
\hline $0^{\circ}$ & $1.74(5)$ & 0.45 & - & 178 & 210 & 7.9 \\
\hline $60^{\circ}$ & $1.27(5)$ & 0.51 & $1.81(5)$ & 192 & 237 & 8.0 \\
\hline $65^{\circ}$ & $1.17(5)$ & 0.49 & $1.78(5)$ & 196 & 246 & 8.1 \\
\hline $70^{\circ}$ & $1.05(5)$ & 0.46 & $1.72(5)$ & 214 & 282 & 9.6 \\
\hline $75^{\circ}$ & $9.3(4)$ & 0.45 & $1.70(5)$ & 222 & 302 & 9.7 \\
\hline $80^{\circ}$ & $7.8(4)$ & 0.37 & $1.41(5)$ & 237 & 337 & 10.7 \\
\hline $85^{\circ}$ & $6.1(4)$ & - & - & 261 & 410 & 15.2 \\
\hline $90^{\circ}$ & $4.7(4)$ & - & - & 288 & 531 & 17.6 \\
\hline
\end{tabular}

${ }^{\mathrm{a}}$ Read as $1.11 \times 10^{5}$.

to rise above that for a temperature independent ion loss rate. Thus the ion density profile near the peak is inherently broader and has a different shape than that of a theoretical Chapman peak.

[51] From a study of the electron density profiles from the Mariners 4, 6, 7, and 9 and the Viking landers, Bauer and Hantsch [1989] proposed that the neutral temperature at the $F_{1}$ peak did not vary as much as the exospheric temperature over a solar cycle. They found that at the electron density peak, $H_{n} \propto F_{10.7}^{0.16}$. A comparison of our model values of $H_{n}$ for high and low solar activities at various solar zenith angles leads to exponents of $F_{10.7}$ that vary from -0.11 to 0.45 . This difference is largely a result of using different shapes for our low and high solar activity neutral temperature profiles and of having only two data points for each SZA.

\subsection{Peak Densities}

[52] The computed density maxima for the $F_{1}$ and $E$ peaks for the low and high solar activity models are plotted as a function of $\cos \chi$ from 60 to $90^{\circ}$ in Figure 11. As the
SZA increases from 70 to $85^{\circ}$, the approximate range of the MGS RS data, the magnitudes of the predicted $F_{1}$ peaks decrease from $7.2 \times 10^{4}$ to $4.4 \times 10^{4} \mathrm{~cm}^{-3}$ at low solar activity, and from $1.05 \times 10^{5}$ to $6.1 \times 10^{4} \mathrm{~cm}^{-3}$ at high solar activity. The $E$ peaks decrease from $3.5 \times 10^{4}$ to $1.9 \times$ $10^{4} \mathrm{~cm}^{-3}$, and from $5.5 \times 10^{4}$ to $3.0 \times 10^{4} \mathrm{~cm}^{-3}$, for the low and high solar activity models, respectively, over the same SZA range.

[53] We can compare our model peak densities at $80^{\circ} \mathrm{SZA}$ to those determined by Bougher et al. [2001] for the first MGS occultation season, for which solar activity was moderate, and the solar zenith angle was $79-81^{\circ}$. Bougher et al. reported a mean $F_{1}$ peak density of $8.1 \times 10^{4} \mathrm{~cm}^{-3}$ and an $E$ peak density of $4 \times 10^{4} \mathrm{~cm}^{-3}$. The mean $F_{1}$ peak densities derived from the first five MGS data sets by Bougher et al. [2004] were in the range $(7.3-8.5) \times 10^{4} \mathrm{~cm}^{-3}$ for solar zenith angles of $78-82^{\circ}$ and moderate solar activity. Our model values for both peak densities at $80^{\circ} \mathrm{SZA}$ are somewhat smaller: the $F_{1}$ peak densities are $(5.6-7.8) \times 10^{4} \mathrm{~cm}^{-3}$, and the $E$ peak densities

Table 4. Characteristics of Model Electron Density E-Region Peaks for Low and High Solar Activities

\begin{tabular}{|c|c|c|c|c|c|c|}
\hline$\underline{\mathrm{SZA}}$ & Maximum Density, $\mathrm{cm}^{-3}$ & Predicted $k$ & Predicted $n_{\max , 0}^{e}, \mathrm{~cm}^{-3}$ & $T_{n} \mathrm{~K}$ & $T_{e}, \mathrm{~K}$ & Scale Height, km \\
\hline \multicolumn{7}{|c|}{ Low Solar Activity } \\
\hline $0^{\circ}$ & $6.2(4)^{\mathrm{a}}$ & 0.52 & - & 139 & 139 & 7.3 \\
\hline $60^{\circ}$ & $4.3(4)$ & 0.53 & $6.3(4)$ & 140 & 140 & 7.2 \\
\hline $65^{\circ}$ & $4.0(4)$ & 0.52 & $6.2(4)$ & 140 & 140 & 7.2 \\
\hline $70^{\circ}$ & $3.5(4)$ & 0.51 & $6.1(4)$ & 140 & 140 & 7.4 \\
\hline $75^{\circ}$ & $3.1(4)$ & 0.49 & $6.0(4)$ & 140 & 140 & 7.5 \\
\hline $80^{\circ}$ & $2.5(4)$ & 0.42 & $5.3(4)$ & 140 & 140 & 7.7 \\
\hline $85^{\circ}$ & $1.9(4)$ & - & - & 141 & 141 & 8.1 \\
\hline $90^{\circ}$ & $1.16(4)$ & - & - & 143 & 147 & 8.7 \\
\hline \multicolumn{7}{|c|}{ High Solar Activity } \\
\hline $0^{\circ}$ & $9.2(4)$ & 0.48 & - & 133 & 133 & 7.2 \\
\hline $60^{\circ}$ & $6.6(4)$ & 0.49 & $9.3(4)$ & 134 & 134 & 7.3 \\
\hline $65^{\circ}$ & $6.1(4)$ & 0.49 & $9.3(4)$ & 134 & 134 & 7.3 \\
\hline $70^{\circ}$ & $5.5(4)$ & 0.48 & $9.2(4)$ & 135 & 135 & 7.2 \\
\hline $75^{\circ}$ & $4.8(4)$ & 0.46 & $9.0(4)$ & 136 & 136 & 7.1 \\
\hline $80^{\circ}$ & $4.0(4)$ & 0.40 & $8.1(4)$ & 140 & 140 & 7.1 \\
\hline $85^{\circ}$ & $3.0(4)$ & - & - & 155 & 155 & 7.4 \\
\hline $90^{\circ}$ & $2.2(4)$ & - & - & 189 & 241 & 8.0 \\
\hline
\end{tabular}

${ }^{\mathrm{a}} \mathrm{Read}$ as $6.2 \times 10^{4}$ 


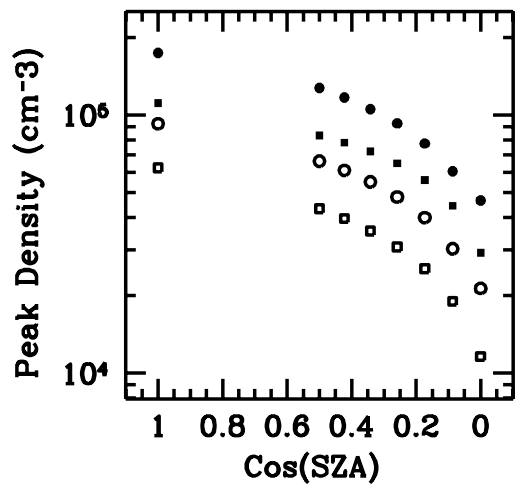

Figure 11. Model $F_{1}$ and $E$ peak densities as a function of $\cos (\mathrm{SZA})$. The circles are those for high solar activity and the squares are for low solar activity. The filled symbols are the $F_{1}$ peaks and the open symbols are the $E$ peaks.

are $(2.5-4.0) \times 10^{4} \mathrm{~cm}^{-3}$ where the range is from low to high solar activities.

[54] Martinis et al. [2003] analyzed the second MGS RS season, which consists of 17 electron density profiles obtained between 9 and 27 March 1999. The values of $F_{10.7}$ during this time period varied from 105 to 153 . The MGS main peak densities were in the range $\sim(7-9) \times$ $10^{4} \mathrm{~cm}^{-3}$. They modeled the densities using the S2K v1.24 solar fluxes of Tobiska [2004] and predicted an $F_{1}$ peak density of $8.5 \times 10^{4} \mathrm{~cm}^{-3}$. The median $F_{1}$ peak density that we derived for MGS occultation seasons 1,2 , and 4 , for higher solar activity conditions $\left(F_{10.7}=140-\right.$ 190) is $8.7 \times 10^{4} \mathrm{~cm}^{-3}$.

[55] Thus compared to the measurements and other models, it appears that our predicted peak densities are somewhat too small. The use of the S2K v2.22 solar flux model of Tobiska [2004] in general gives ion peak densities that are $20-30 \%$ smaller than those computed with the S2K v1.24 models, or with the Hinteregger solar flux models, which we have used previously [e.g., Fox, 2004]. For example, the model $F_{1}$ peak density for the present $60^{\circ}$ SZA S2K v2.22 high solar activity model is $1.27 \times 10^{5}$, but increases to $1.76 \times 10^{5} \mathrm{~cm}^{-3}$ when the S2K v1.24 solar fluxes are adopted. There is a similar discrepancy between the measured and model electron density profiles for Venus computed with the S2K v1.24 and v2.22 fluxes [e.g., Fox and Paxton, 2005; J. Fox, submitted manuscript, 2006].

[56] We fitted the model peak densities for each $5^{\circ}$ solar zenith angle interval to equation (8), and derived values of the exponent $k$ and intercept $A\left(n_{0, \text { max }}^{i}\right)$, which are shown at the lower solar zenith angle for each interval in Tables 3 and 4. There are no predictions for the interval $85-90^{\circ}$ because $\cos \left(90^{\circ}\right)$ is zero, and, as most investigators, we do not use a Chapman function for the inverse cosine. The values computed for the $0^{\circ} \mathrm{SZA}$ models are shown for reference only. For the $F_{1}$ peak, as the solar zenith angle increases from 60 to $85^{\circ}$, the values of $k$ decrease from 0.38 to 0.34 at low solar activity, and from 0.51 to 0.37 at high solar activity. The decrease in the value of $k$ as the SZA interval increases reflects, in part, the increasing effect of spherical geometry as the terminator is approached. This is because the plane parallel approximations on which equations (2) and (7) are based, break down near the terminator. The column densities above a given altitude for a given SZA are smaller for a spherical atmosphere than for a plane parallel atmosphere, and thus the values of $n_{\text {max }, 0}^{i}$ derived from models of the near terminator ionosphere are not expected to exhibit high accuracy. The predicted values of $n_{\max , 0}^{i}$ are in the ranges $(1.0-1.1) \times 10^{5}$ and $(1.4-1.8) \times 10^{5} \mathrm{~cm}^{-3}$ for the low and high solar activity models, respectively.

[57] In Figure 12, $\log n_{\max , \chi}^{i}$ is plotted against $\log \cos \chi$ for solar zenith angles 60 to $85^{\circ}$, and the linear least squares fit to each set of model electron density peaks is also shown. The models for solar zenith angles of 0 and $90^{\circ}$ are excluded from this fit. The slopes of the lines are the exponents $k$ in equation (8) and the curves are labeled by the values for each set of calculations. For the model $F_{1}$ peak, the best fit values of $k$ are 0.45 and 0.43 , for low and high solar activities, respectively.

[58] For the $E$ peak, the computed values of $k$ decreases from 0.53 to 0.42 for the low solar activity model, and from 0.49 to 0.40 for the high solar activity model, as the SZA intervals increase from $60-65^{\circ}$ to $80-85^{\circ}$. The individual intervals for $75^{\circ}$ or less yield values for $k$ that appear to be close to the "Chapman" value of 0.5. Since for the nearterminator ionosphere we expect smaller values of $k$ for the Chapman expression (8), a value of 0.5 is actually "nonChapman." When all the $E$ peak densities for the solar zenith angle range $60-85^{\circ}$ are plotted against SZA, the overall slopes of the linear least squares fits are 0.43 and 0.45 for the low and high solar activity models, respectively. The predicted values for $n_{\text {max }, 0}^{i}$ decrease from $6.3 \times 10^{4}$ to $5.3 \times 10^{4} \mathrm{~cm}^{-3}$ at low solar activity and from $9.3 \times 10^{4}$ to $8.1 \times 10^{4} \mathrm{~cm}^{-3}$ at high solar activity, from the $60-65^{\circ}$ to the $80-85^{\circ} \mathrm{SZA}$ intervals.

[59] Our model best fit values for $k$ at the $F_{1}$ peak of 0.45 and 0.43 for low and high solar activities, respectively, are slightly smaller than that derived from the moderate solar activity MGS data $(0.465 \pm 0.010)$. This may be due in part to the assumed model-invariant electron temperature profile, which results in increases in $T_{e}$ with SZA at the peaks. At the $F_{1}$ peak, $T_{e}$ increases from 192 to $331 \mathrm{~K}$ at low solar activity, and from 237 to $531 \mathrm{~K}$ at high solar activity as the SZA increases from 60 to $90^{\circ}$. The largest increase is from 85 to $90^{\circ} \mathrm{SZA}$. As stated previously, larger values of $T_{e}$ at the peak increase the peak density and partially compensate

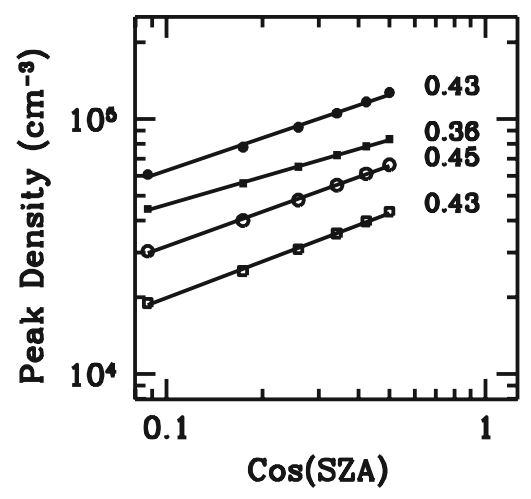

Figure 12. Log-log plot of model peak density as a function of $\cos (\mathrm{SZA})$. The symbols are as in Figure 11. The best fit linear regressions are shown. The curves are labeled by the slopes, $k$. 
for the decrease in ion densities that arises from the increase of SZA. Equations (2) to (6) show that the maximum densities should be inversely proportional to $H_{n}^{0.5}$ and proportional to $T_{e}^{0.35}$. Since the two parameters at the $F_{1}$ peaks in the model increase as the solar zenith angle increases, the overall effect is that variations in the parameters would be expected to cancel each other out somewhat.

[60] Nevertheless, the model $F_{1}$ peaks do not seem to follow Chapman theory as expressed by equation (7). More important, however, is that the exponents $k$ for the model $F_{1}$ peaks are significantly smaller than the values $(0.5-0.57)$ derived by previous investigators. The solar zenith angle range of the data analyzed by, for example, Hantsch and Bauer [1990] and Zhang et al. [1990] was larger, and they derived $k$ values of 0.57 from the existing pre-MGS electron density profiles. Martinis et al. [2003], however, analyzed solar zenith angle variations of the $F_{1}$ peak for the second season of MGS data, which is in the near terminator region, and found that they approximated that of a Chapman layer, with $(\cos \chi)^{0.5}$. Unless the precision of the $k$ value derived by Martinis et al. was limited to one decimal place, their value is slightly larger than our derived value of $0.465 \pm$ 0.010 for the MGS peaks for the $F_{10.7}$ range $140-190$, which is in turn slightly larger than the values 0.43 and 0.45 derived from our high and low solar activity models, respectively.

[61] Table 4 shows the variation in the neutral and electron temperatures and in the neutral scale heights as a function of SZA for the model $E$ peaks in the 60 to $90^{\circ}$ range. The temperature variations are small for solar zenith angles of $85^{\circ}$ or less at low solar activity, and for solar zenith angles less than $80^{\circ}$ at high solar activity. These characteristics by themselves would tend to result in "Chapmanlike" behavior, and a coefficient $k$ closer to $\sim 0.5$ at low solar activity, although the characteristics of $E$ layers are such that we expect them to be less Chapman-like than the $F_{1}$ layers. We find, however, that the overall best fit values for $k$ are 0.43 for low solar activity and 0.36 for high solar activity at the $E$ peaks. Both values are, however, significantly smaller than the value $0.551 \pm 0.024$ derived from the MGS data. This model values of $k$ reflect in part variations in the assumed values of $T_{e}$ and in $H_{n}$. As mentioned previously, we also expect that the use of spherical rather than plane parallel geometry in models in the near terminator region would reduce the value of $k$ below the value 0.5 for the ideal Chapman layer as expressed by equation (7), even if the other parameters are assumed to be Chapman-like. For spherical geometry, the computed peak electron densities are larger than those for a plane parallel atmosphere, and thus the SZA dependence of $k$ is decreased. That this effect increases in importance as the solar zenith angle approaches the terminator is shown in Tables 3 and 4, where the derived values of $k$ decrease with increases in the solar zenith angle ranges. The discrepancy between the model values of $k$ and those derived by fitting to the MGS data, however, constitutes significant evidence that there are changes in the thermosphere as a function of SZA that are not reflected in the model.

[62] The error produced by the effect of spherical geometry can be reduced by substituting a Chapman function $C h(x, \chi)$ for the sec $\chi$ [e.g., Chapman, 1931b]. The assumed parameters in the Chapman function fitted by Gurnett et al.
[2005] to the 14 August 2005 MARSIS electron density profile at a solar zenith angle of $89.3^{\circ}$ were $H_{n}=25 \mathrm{~km}$ and $x=141$, and the resulting value of $C h(x, \chi)$ was 13.5 . The value of the Chapman function can be compared to the ratio of the numerically integrated neutral densities above $195 \mathrm{~km}$ at $90^{\circ}$ to those at $0^{\circ}$ of 15.5 in our low solar activity model. Our model value of $H_{n}$ at $195 \mathrm{~km}$ of $15.8 \mathrm{~km}$ is, however, significantly smaller than that assumed by Gurnett et al. [2005].

[63] The predicted subsolar $F_{1}$ peak densities, $A=n_{\max , 0}^{i}$, derived from our linear fits to Equation (8) to the model peaks shown in Figure 12 are $1.07 \times 10^{5}$ and $1.68 \times 10^{5} \mathrm{~cm}^{-3}$, for low and high solar activities, respectively; the analogous predicted subsolar $E$ peak densities are $5.9 \times 10^{4}$ and $8.9 \times 10^{4}$, respectively. The values of the $F_{1}$ subsolar peak densities are consistent with those derived by Bauer and Hantsch [1989] of $1 \times 10^{5} \mathrm{~cm}^{-3}$ for Viking (low solar activity) conditions and $1.6 \times 10^{5} \mathrm{~cm}^{-3}$ for Mariner 6 (moderately high solar activity) conditions. Zhang et al. [1990], however, derived somewhat larger subsolar $F_{1}$ peak densities of $(1.5-2.3) \times 10^{5} \mathrm{~cm}^{-3}$ from their analysis of pre-MGS data. Similarly, Hantsch and Bauer [1990] derived a single value for $n_{\max , 0}^{i}$ of $2 \times 10^{5} \mathrm{~cm}^{-3}$. Breus et al. [1998, 2004] reported larger values for Viking and Mariner 9 conditions (low to moderate solar activity) of $(1.77-1.97) \times 10^{5} \mathrm{~cm}^{-3}$.

[64] Gurnett et al. [2005] fitted the $89.1^{\circ}$ SZA MEX MARSIS profile from 14 August 2005 to a Chapman profile, and predicted a subsolar peak electron density of $1.32 \times 10^{5} \mathrm{~cm}^{-3}$ at an altitude of $130 \mathrm{~km}$. As mentioned previously, in our model, the upper boundary of the PCE region for the $90^{\circ}$ low solar activity model is near $170 \mathrm{~km}$. Thus fitting this profile to a Chapman layer, even if the sec $\chi$ is replaced by a Chapman function, may be inappropriate. Gurnett et al. also derived a best fit subsolar maximum electron density for all of the profiles for 12 MEX orbits between 5 July 2005 and 10 October 2005, and reported a fairly high value of $1.98 \times 10^{5} \mathrm{~cm}^{-3}$. This whole period was one of generally low solar activity, with $F_{10.7}$ ranging from about 73 to 130 .

[65] A major reason for the discrepancy between the parameters $k$ for the $F_{1}$ and $E$ peak densities derived from the data and those of our models is that our model values for $T_{e}$ at the ion peaks may be unrealistically high. Owing to the assumption of a constant $T_{e}$ profile for all the models, the value of $T_{e}$ at the $F_{1}$ peak increases significantly for both the low and high solar activity models as the SZA increases. As the values of $T_{e}$ increase, the ion loss rates decrease, leading to larger ion peak densities. Thus a smaller variation of the peak densities with solar zenith angle would be predicted, which translates into smaller model values of $k$.

[66] The Martian ion temperature profiles were only measured by the Viking RPAs during solar minimum for a solar zenith angle of $\sim 45^{\circ}$ [Hanson et al., 1977]. Hanson and Mantas [1988] reported values of $T_{e}$ measured by the Viking RPA's above $200 \mathrm{~km}$. Calculations of electron temperature profiles were made by Chen et al. [1978] and Rohrbaugh et al. [1979]. Our assumed values for $T_{e}$ below $200 \mathrm{~km}$ are based on the latter calculations. It has been found to be difficult to model the plasma temperatures without imposing an ad hoc heat source at the top of the 
models [e.g., Johnson, 1978; Chen et al., 1978; Choi et al., 1998; Nagy and Cravens, 2002].

[67] In the lower thermosphere/ionosphere, where the neutral number densities are large and collisions are frequent, $T_{n}, T_{i}$, and $T_{e}$ are equal. The ambient electrons are heated by collisions with the suprathermal electrons produced in photoionization, and the departure of the electron temperature profile from the neutral temperature profile probably occurs near the ionization peak, which rises with solar zenith angle. Our electron temperatures begin to diverge (unrealistically) from the neutral temperatures near $130 \mathrm{~km}$ in all the models. The electrons cool by excitation of the fine structure levels of $\mathrm{O}\left({ }^{3} P_{2,1,0}\right)$, by downward conduction, and by coulomb collisions with the ambient ions and electrons, both of which decrease in density with increases in the SZA [e.g., Schunk and Nagy, 2000]. Unfortunately, there are no calculations or measurements of the variation of $T_{i}$ or $T_{e}$ with SZA in the Martian ionosphere.

[68] The $T_{e}$ profile in the Venus ionosphere has been found to be nearly independent of solar zenith angle [e.g., Miller et al., 1980]. An inverse correlation between $n^{e}$ and $T_{e}$ in the Venus ionosphere has, however, been found by Knudsen et al. [1979], Dobe et al. [1993], and Mahajan et al. [1994]. Breus et al. [2004] have adduced evidence from analysis of some of the MGS profiles that $T_{e}$ and $E_{10.7}$ in the Martian ionosphere are anticorrelated. $\left(E_{10.7}\right.$ is the integrated solar energy flux in the 1 to $100 \mathrm{~nm}$ region in the S2K models, expressed in $F_{10.7}$ units [e.g., Tobiska, 2004].) We thus might expect that at large solar zenith angles, where the peak electron densities are smaller than those at $60^{\circ}$, some increase in $T_{e}$ may actually be realistic. The uncertainties in the electron temperature profiles are among the largest sources of error in our models. We note here also, however, that the values of $T_{e}$ in the Venus ionosphere have been found to be partly controlled by the interaction of the ionosphere with the solar wind [e.g., Brace et al., 1980], and with the presence or absence of an induced magnetospheric field [e.g., Dobe et al., 1993].

[69] Various investigators have determined the solar activity variation of the electron peak densities, generally expressed as

$$
\log n_{\max , \chi}^{e} \propto\left(\log F_{10.7}\right)^{m}
$$

Since we have constructed models for only two values for $F_{10.7}, 68$ and 207, we have estimated the exponents $m$ in equation (9) from the ratio of the $F_{1}$ peak density of the high solar activity model to that of the low solar activity model for each solar zenith angle. We find that the derived values of $m$ are $0.38,0.36,0.34,0.32,0.30,0.29$, and 0.41 for solar zenith angles of $60,65,70,75,80,85$, and $90^{\circ}$, respectively. These exponents are in substantial agreement with those derived by Breus et al. [2004], for a subset of the MGS orbits in occultation season 4, for their "corrected" values of the peak densities, $n_{\max , \chi}^{e}\left(H_{n} / \cos \chi\right)^{0.5}$ vs $E_{10.7}$ of $0.37 \pm$ 0.06. For pre-MGS data, Hantsch and Bauer [1990] derived a similar value of 0.36 for the exponent in equation (9) above. This solar activity variation of $n_{\max , \chi}^{e}$ on Mars is similar to that reported for the peak electron densities at Venus as a function of $F_{10.7}$ by Kliore and Mullen [1989] from an analysis of 115 radio occultation profiles from the
PV ORO. They derived an equation that represents a best fit to the maximum electron densities as a function of solar activity and $\chi$ :

$$
\begin{aligned}
& n_{\max }^{e}\left(F_{\text {euv }}, \chi\right)=(5.92 \pm 0.03) \times 10^{5} \\
& \quad \times\left(F_{\text {euv }} / 150\right)^{0.376 \pm 0.011}(\cos \chi)^{0.511 \pm 0.012}
\end{aligned}
$$

where $F_{\text {euv }}$ is an estimated value of $F_{10.7}$ corrected to the position of Venus. Note that the exponent of $\cos \chi, 0.511$, is apparently "Chapman-like."

\subsection{Topside Scale Heights}

[70] In Table 5 we present the neutral density scale heights, $H_{n}$, the ion (or electron) density scale heights $H_{i}$, and the plasma pressure scale heights $H_{p}$ at altitudes that are $33 \mathrm{~km}$ above the ion peaks for all of the models. Because the peak rises as the solar zenith angle increases, the altitudes at which the scale heights are evaluated also increase. Also shown in Table 5 are values for $H_{i}$ and $H_{p}$ at $250 \mathrm{~km}$ for each model. The values of $H_{n}$ and $H_{i}$ were determined numerically from the model neutral and electron density profiles. The values of $H_{p}$ were computed as $k\left(T_{e}+T_{i}\right) /$ $\left(m_{a}^{i} g\right)$, where $m_{a}^{i}$ is the average mass of the ions. The values of $H_{i}$ and the ratios $H_{i} / H_{n}$ at high solar activity for the 70 and $75^{\circ}$ models are anomalously large and are artifacts that result from slope discontinuities in the ion and electron temperature profiles, which are shown in Figure 2.

[71] In Chapman theory, the atmosphere is assumed to be isothermal. The values of $H_{n}$, at the peaks, as shown in Table 3, are, however, significantly smaller than those $33 \mathrm{~km}$ above the peak, as shown in Table 5. This reflects mostly the rise of the assumed neutral temperatures in this region of the model. The scale height is also inversely proportional to the acceleration of gravity, which decreases slowly with altitude, but this contributes negligibly to the increase in scale heights over a $33 \mathrm{~km}$ altitude range.

[72] The ratios of $H_{i}$ to $H_{n}$ at $33 \mathrm{~km}$ above the ion peak are listed in the fifth column of Table 5. Chapman theory (equation (5)) suggests that the ion density scale heights above the peak should be twice the neutral density scale heights. The model ratios $H_{i} / H_{n}$ for low solar activity vary from 2.3 to 1.19 , as the SZA increases from 60 to $90^{\circ}$. The larger values for $60^{\circ} \mathrm{SZA}$ are also related the non-Chapman factors discussed earlier which cause the broadening of the peaks. The values of $H_{i}$, and the $H_{i} / H_{n}$ ratio decrease sharply with increasing SZA for values greater than $80^{\circ}$. This is because the altitudes at which the scale heights are computed are above the PCE region, where the ion densities decrease at a larger rate owing to the upward flux boundary conditions at the top of the model [cf., Chen et al., 1978; Fox, 1993, 1997]. Thus the ratio $H_{i} / H_{n}$ falls below 2 for the larger solar zenith angles. The values of $H_{i}$ should also deviate from twice the neutral scale height because the ion density depends on the dissociative recombination coefficient, which is proportional to $T_{e}^{-0.35}$. As noted previously, the model electron temperatures at the electron density peaks increase with altitude. This is also true at altitudes above the peak. This effect has also been noted by Hantsch and Bauer [1990], Zhang et al. [1990], and Breus et al. [2004].

[73] Table 5 also shows that the values of $H_{i}$ are significantly less than those of the plasma pressure scale height 
Table 5. Model Topside Neutral, Ion and Plasma Pressure Scale Heights at $33 \mathrm{~km}$ Above the Peak and at $250 \mathrm{~km}$, as a Function of SZA, $\mathrm{km}$, and ratio of $H_{i}$ and $H_{n}$.

\begin{tabular}{|c|c|c|c|c|c|c|c|}
\hline SZA & Altitude, ${ }^{\mathrm{a}} \mathrm{km}$ & $\begin{array}{c}\text { Neutral Scale } \\
\text { Height }^{\mathrm{a}}\end{array}$ & Ion Scale Height ${ }^{\mathrm{a}}$ & Ratio & $\begin{array}{l}\text { Plasma Pressure } \\
\text { Scale Height }{ }^{\mathrm{a}, \mathrm{c}}\end{array}$ & Ion Scale Height $^{\mathrm{b}}$ & $\begin{array}{l}\text { Plasma Pressure } \\
\text { Scale Height }{ }^{\mathrm{b}, \mathrm{c}}\end{array}$ \\
\hline \multicolumn{8}{|c|}{ Low Solar Activity } \\
\hline $60^{\circ}$ & 169 & 11.4 & 25.8 & 2.3 & 44.1 & 59.7 & 287 \\
\hline $65^{\circ}$ & 170 & 11.6 & 26.3 & 2.3 & 44.9 & 59.7 & 287 \\
\hline $70^{\circ}$ & 172 & 11.7 & 26.9 & 2.3 & 45.8 & 59.7 & 287 \\
\hline $75^{\circ}$ & 174 & 12.1 & 29.2 & 2.4 & 47.4 & 59.7 & 287 \\
\hline $80^{\circ}$ & 177 & 12.4 & 23.4 & 1.88 & 47.4 & 59.8 & 287 \\
\hline $85^{\circ}$ & 182 & 13.2 & 15.0 & 1.13 & 56.0 & 59.8 & 286 \\
\hline $90^{\circ}$ & 190 & 14.7 & 17.4 & 1.19 & 82.1 & 59.8 & 286 \\
\hline \multicolumn{8}{|c|}{ High Solar Activity } \\
\hline $60^{\circ}$ & 170 & 18.1 & 51.8 & 2.9 & 57.0 & 43.0 & 275 \\
\hline $65^{\circ}$ & 171 & 17.7 & 54.2 & 3.1 & 57.6 & 46.4 & 303 \\
\hline $70^{\circ}$ & 175 & 16.9 & $120.2^{\mathrm{d}}$ & $7.1^{\mathrm{d}}$ & 59.3 & 46.5 & 303 \\
\hline $75^{\circ}$ & 177 & 17.2 & $86.0^{\mathrm{d}}$ & $5.0^{\mathrm{d}}$ & 60.8 & 46.5 & 303 \\
\hline $80^{\circ}$ & 181 & 20.1 & 54.7 & 2.7 & 67.6 & 46.6 & 303 \\
\hline $85^{\circ}$ & 191 & 22.0 & 36.3 & 1.65 & 101 & 46.7 & 303 \\
\hline $90^{\circ}$ & 211 & 24.3 & 33.1 & 1.36 & 165 & 47.0 & 303 \\
\hline
\end{tabular}

${ }^{\mathrm{a}}$ Here, $33 \mathrm{~km}$ above ion peak.

${ }^{\mathrm{b}}$ At $250 \mathrm{~km}$.

${ }^{\mathrm{c}}$ Computed as $k\left(T_{e}+T_{i}\right) / m_{a}^{i} g$, where $T_{e}$ and $T_{i}$ are the electron and ion temperatures, $m_{a}^{i}$ is the average mass of the ions, and $g$ is the acceleration of gravity.

${ }^{\mathrm{d}}$ These points are anomalous. They are associated with slope discontinuities of the electron and ion temperature profiles.

$H_{p}$ both at $33 \mathrm{~km}$ above the ion peak and at $250 \mathrm{~km}$. In a stationary ionosphere, the ion density and plasma pressure scale heights are related by

$$
\frac{1}{H_{i}}=\frac{1}{H_{p}}+\frac{1}{T_{p}} \frac{d T_{p}}{d z}
$$

where $T_{p}=\left(T_{e}+T_{i}\right)$ is the plasma temperature. Thus at altitudes where the plasma temperatures are increasing, the values of the ion density scale heights will be substantially smaller than the plasma pressure scale heights, even in the absence of the assumed upward fluxes. Therefore the ion density profiles cannot be used to determine the values of $T_{e}+T_{i}$ by fitting the observed topside scale heights to the expression $k\left(T_{e}+T_{i}\right) / m_{a}^{i} g$, as they could be if the ion densities were in diffusive equilibrium in an isothermal atmosphere.

[74] We have evaluated the solar activity variations of the ion scale height $33 \mathrm{~km}$ above the electron density peaks in our model by fitting the exponent $n$ in the formula $H_{i} \propto$ $F_{10.7}^{n}$. Values of $0.63,0.65,0.76,0.79$, and 0.58 are determined for solar zenith angles of $60,65,80,85$, and $90^{\circ}$, respectively. These values are somewhat larger than that reported by Bauer and Hantsch [1989], who found a best-fit value for $n$ of 0.55 for the topside electron densities obtained from radio occultation measurements on the Mariner 4, 6, 7, and 9 spacecraft, the Mars 2, 3, 4, and 6 spacecraft, and in situ data from the two Viking Landers. Our derived values are based, however, on only two points for each SZA.

\section{Summary and Conclusions}

[75] We have analyzed the MGS electron density profiles for seasons 1,2, and 4, and recorded the $F_{1}$ and $E$ peak electron densities, the altitudes of the peaks, the solar zenith angles, and the $F_{10.7}$ values corrected for the orbital position of Mars. For each day we have selected for analysis one profile that exhibits the median $F_{1}$ peak density for that day. We plot the logs of the maximum densities against the log of the SZA, and present values for the slope $k$ and predicted subsolar maximum densities, $A\left(n_{\max , 0}^{i}\right)$, in equation (8). We find that for the $F_{10.7}$ range $140-190$, the derived values for $k$ are $0.465 \pm 0.010$ and $0.551 \pm 0.024$, and the predicted subsolar peak densities are $(1.82 \pm 0.03) \times 10^{5}$ and $(9.4 \pm$ $0.4) \times 10^{4} \mathrm{~cm}^{-3}$ for the $F_{1}$ and $E$ peaks, respectively. The data from the other $F_{10.7}$ ranges are not well distributed over longitude, and therefore the derived values of $k$ and $A$ are of limited validity. As more RO profiles are included in our data sets, better statistics will lead to more secure conclusions.

[76] We have also constructed models of the low and high solar activity Martian thermospheres/ionospheres for solar zenith angles from 60 to $90^{\circ}$ in $5^{\circ}$ intervals. The background neutral atmospheres are similar to those that we have adopted recently [Fox, 2004]. We have presented altitude profiles of the ion production rates from photoionization and electron impact ionization, and the resulting total ion or electron densities. As expected, the profiles exhibit two peaks, which are somewhat smaller in magnitude than those measured by the MGS radio science measurements. As explained previously, we attribute this to the use of the S2K 2.22 solar flux model of Tobiska [2004], which gives ion peak densities that are $20-30 \%$ smaller that those obtained using the S2K v1.24 solar flux model, or the Hinteregger solar fluxes that we have used previously [Fox, $2004]$. We also find that the model $F_{1}$ peaks for solar zenith angles less than $\sim 85^{\circ}$ are considerably higher in the atmosphere than the radio occultation peaks for nondusty conditions. This implies that the neutral temperatures and densities at a given angle do decrease somewhat as the terminator is approached. We have fitted the model maximum electron densities as a function of $\cos \chi$ to the Chapman formula, equation (8), and predict values of the slope $k$ and the intercept $A$. Our derived values for $k$ are 0.43 and 0.46 for the high solar activity model $F_{1}$ and $E$ peaks, respectively and 0.36 and 0.43 for the low solar 
activity $F_{1}$ and $E$ peaks, respectively. All the model $k$ values are less than the "Chapman" value of 0.5 . We argue, however, that the use of spherical geometry by itself causes the value of $k$ to decrease below the Chapman value, as expressed by equation (8), in the near-terminator region. Thus a perfect Chapman profile in the near terminator region would be characterized by a value of $k$ that is less than 0.5 .

[77] That the model values of $k$ are smaller than those derived from the MGS electron density profiles, which are all in the near terminator region, is more important. The peak magnitudes and heights depend on the altitude profiles of $T_{n}, T_{i}$, and $T_{e}$, and the neutral density profiles. That the peak altitudes are too high could partially be explained by a small vertical offset of all the models. As evidenced also by the peak altitudes, the discrepancy between the model $k$ values and those derived from the MGS data implies also that the neutral atmosphere appears to be solar zenith angle dependent. Electron temperatures that are too large and increase too strongly at the peak altitude as the solar zenith angle increases also contribute to the smaller predicted values of $k$. The variations of the $T_{e}$ profiles with SZA and with solar activity are among the largest uncertainties in the model. We conclude that the actual values of $T_{e}$ at the ion peaks probably do not increase with increasing solar zenith angle as rapidly as they do in our models.

[78] We also argue that there are factors due to the expected non-Chapman behavior, that broaden and reshape the electron density profiles, which limits the accuracy of values of $H_{n}$ or $T_{e}$ derived by fitting the measured electron density profiles in the region of the peak to theoretical Chapman profiles. This broadening of the peak, along with the increase in $T_{n}$ above the peak also leads to inferred values of ion scale heights $H_{i} 33 \mathrm{~km}$ above the peak that are larger than twice the value of $H_{n}$ at the peak for the smaller solar zenith angles models. For larger solar zenith angles, the ratio $H_{i} / H_{n}$ is less than 2 because the altitude where $H_{i}$ is evaluated is above the PCE boundary. The ion or electron scale height in this region is decreased due to the assumption of upward flux boundary conditions, which probably reflect the interaction of the solar wind with the thermosphere. We also find that the peak densities for the $90^{\circ}$ models are near or above the PCE boundary. Therefore fitting the electron density profiles for solar zenith angles approaching or larger than $90^{\circ}$ to Chapman profiles may be inappropriate.

[79] Solar activity variations of the model $F_{1}$ peaks as expressed by the exponents $m$ in the expression $n_{\max , \chi}^{e} \propto\left(\log F_{10.7}\right)^{m}$ which range from 0.29 to 0.41 for the seven solar zenith angle models are in good agreement with those derived by other workers. The values of the exponent are also similar to the value of $0.376 \pm 0.011$ derived for Venus by Kliore and Mullen [1989].

[80] Finally, we note that unlike many of the MGS profiles, our models exhibit a shoulder rather than a distinct minimum between the $F_{1}$ and $E$ peaks, as shown by the profiles in Figures 1 and 9. This is a subject for further study.

[81] Acknowledgments. This work has been supported by grants NAG5-12755 and MAG5-13313 from the National Aeronautics and Space Administration. The Solar2000 research grade irradiances are provided courtesy of W. Kent Tobiska and SpaceWx.com. These historical irradiances have been developed with funding from the NASA UARS, TIMED, and SOHO missions.
[82] Wolfgang Baumjohann thanks Martin Paetzold and Hiroyuki Shinagawa for their assistance in evaluating this paper.

\section{References}

Alge, E., N. G. Adams, and D. Smith (1983), Measurements of the dissociative recombination coefficients of $\mathrm{O}_{2}^{+}, \mathrm{NO}^{+}$, and $\mathrm{NH}_{4}^{+}$in the temperature range $200-600 \mathrm{~K}, J$. Phys. B., 16, 1433-1444.

Anderson, D. E. (1974), Mariner 6, 7, and 9 ultraviolet spectrometer experiment: Analysis of hydrogen Lyman alpha data, J. Geophys. Res. $79,1513-1518$

Anderson, D. E., and C. W. Hord (1971), Mariner 6 and 7 ultraviolet spectrometer experiment: Analysis of hydrogen Lyman alpha, J. Geophys. Res., 76, 6666-6673.

Ayres, T. (1997), Evolution of the solar ionizing flux, J. Geophys. Res, 102, $1641-1651$

Banks, P. M., and G. Kockarts (1977), Aeronomy, vol. A, pp. 144-146, Elsevier, New York

Bauer, S. J. (1973), Physics of Planetary Ionospheres, Springer, New York.

Bauer, S. J., and M. H. Hantsch (1989), Solar cycle variation of the upper atmosphere temperature of Mars, Geophys. Res. Lett., 16, 373-376.

Bougher, S. W., R. G. Roble, E. C. Ridley, and R. E. Dickinson (1990), The Mars thermosphere: 2. General circulation with coupled dynamics and composition, J. Geophys. Res., 95, 14,811-14,827.

Bougher, S. W., S. Engel, R. G. Roble, and B. Foster (2000), Comparative terrestrial planet thermospheres: 3. Solar cycle variation of global structure and winds at solstices, J. Geophys. Res., 105, 17,669-17,692.

Bougher, S. W., S. Engel, D. P. Hinson, and J. M. Forbes (2001), Mars Global Surveyor Radio Science electron density profiles: Neutral atmosphere implications, Geophys. Res. Lett., 28, 3091-3094.

Bougher, S. W., S. Engel, D. P. Hinson, and J. R. Murphy (2004), MGS Radio Science electron density profiles: Interannual variability and implications for the neutral atmosphere, J. Geophys. Res., 109, E03010, doi:10.1029/2003JE002154

Brace, L. H., R. F. Theis, W. R. Hoegy, J. H. Wolfe, J. D. Mihalov, C. T. Russell, R. C. Elphic, and A. F. Nagy (1980), The dynamic behavior of the Venus ionosphere in response to solar wind interactions, J. Geophys. Res., 85, 7663-7678.

Breus, T. K., K. Yu. Pimenov, M. N. Izakov, A. M. Krymskii, J. G. Luhmann, and A. J. Kliore (1998), Conditions in the Martian ionosphere/atmosphere from a comparison of a thermospheric model with radio occultation data, Planet. Space Sci., 46, 367-376.

Breus, T. K., A. M. Krymskii, D. H. Crider, N. F. Ness, D. Hinson, and K. K. Barashyan (2004), Effect of the solar radiation in the topside atmosphere/ionosphere at Mars: Mars Global Surveyor observations, J. Geophys. Res., 109, A09310, doi:10.1029/2004JA010431.

Chapman, S. (1931a), The absorption and dissociative or ionizing effects of monochromatic radiation in an atmosphere of a rotating Earth, Proc. Phys. Soc. London, 43, 26-45.

Chapman, S. (1931b), The absorption and dissociative or ionizing effects of monochromatic radiation in an atmosphere of a rotating Earth, Part II. Grazing incidence, Proc. Phys. Soc. London, 43, 483-501.

Chen, R. H., T. E. Cravens, and A. F. Nagy (1978), The Martian ionosphere in light of the Viking observations, J. Geophys. Res., 83, 3871-3876.

Choi, Y. W., J. Kim, K. W. Min, A. F. Nagy, and K. I. Oyama (1998), Effects of the magnetic field on the energetics of Mars, Geophys. Res. Lett., 25, 2753-2756.

Cravens, T. E., A. J. Kliore, J. U. Kozyra, and A. F. Nagy (1981), The ionospheric peak on the Venus dayside, J. Geophys. Res., 86, 11,32311,329 .

Dobe, Z., A. F. Nagy, L. H. Brace, R. F. Theis, and C. T. Russell (1993), Energetics of the dayside ionosphere of Venus, Geophys. Res. Lett., 20, $1523-1526$

Fjeldbo, G., and V. R. Eshleman (1968), The atmosphere of Mars analyzed by integral inversion of the Mariner IV occultation data, Planet. Space Sci., 16, 1035-1059.

Fjeldbo, G., A. Kliore, and B. Seidel (1970), The Mariner 1969 occultation measurements of the upper atmosphere of Mars, Radio Sci., 5, 381386.

Forbes, J. M., and M. E. Hagan (2000), Diurnal Kelvin wave in the atmosphere of Mars: Towards and understanding os 'Stationary' density structures, observed by the MGS accelerometer, Geophys. Res. Lett., 27, $3563-3566$

Forbes, J. M., A. F. C. Bridger, M. E. Hagan, S. W. Bougher, J. L. Hollingworth, G. M. Keating, and J. R. Murphy (2002), Non-migrating tides in the thermosphere of Mars, J. Geophys. Res., 107(E11), 5113, doi:10.1029/2001JE001582

Fox, J. L. (1993), The production and escape of nitrogen atoms on Mars, J. Geophys. Res., 98, 3297-3310.

Fox, J. L. (1997), Upper limits to the outflow of ions at Mars: Implications for atmospheric evolution, Geophys. Res. Lett., 24, 2901-2904. 
Fox, J. L. (2003), The effect of $\mathrm{H}_{2}$ on the Martian ionosphere: Implications for atmospheric evolution, J. Geophys. Res., 108(A6), 1223, doi:10.1029/ 2001JA000203

Fox, J. L. (2004), The effects of enhanced fluxes of soft xrays on the Martian ionosphere, J. Geophys. Res., 109, A11310, doi:10.1029/ 2004JA010380.

Fox, J. L., and S. W. Bougher (1991), Structure, luminosity and dynamics of the Venus thermosphere, Space Sci. Rev., 55, 357-489.

Fox, J. L., and A. Dalgarno (1979), Ionization, luminosity and heating of the upper atmosphere of Mars, J. Geophys. Res., 84, 7315-7339.

Fox, J. L., and L. J. Paxton (2005), C and $\mathrm{C}^{+}$in the Venusian thermosphere/ ionosphere, J. Geophys. Res., 110, A01311, doi:10.1029/2004JA010813.

Fox, J. L., and K. Y. Sung (2001), Solar activity variations in the Venus ionosphere/thermosphere, J. Geophys. Res., 106, 21,305-21,335.

Fox, J. L., P. Zhou, and S. W. Bougher (1995), The thermosphere/ionosphere of Mars at high and low solar activities, Adv. Space Res., 17(11), $203-218$.

Gurnett, D. A., et al. (2005), Radar soundings of the ionosphere of Mars, Science, 310, 1929-1933.

Hanson, W. B., and G. P. Mantas (1988), Viking electron temperature measurements: Evidence for a magnetic field in the Martian atmosphere, J. Geophys. Res., 93, 7538-7544.

Hanson, W. B., S. Sanatani, and D. R. Zuccaro (1977), The Martian ionosphere as observed by the Viking retarding potential analyzers, J. Geophys. Res., 82, 4351-4367.

Hantsch, M. H., and S. J. Bauer (1990), Solar control of the Mars ionosphere, Planet. Space Sci., 38, 539-542.

Hinteregger, H. E., K. Fukui, and B. R. Gibson (1981), Observational, reference and model data on solar EUV, from measurements on AE-E, Geophys. Res. Lett., 8, 1147-1150.

Hogan, J. S., R. W. Stewart, and S. I. Rasool (1972), Radio occultation measurements of the Mars atmosphere with Mariners 6 and 7, Radio Sci., 7, 525-537.

Johnson, R. E. (1978), Comment on ion and electron temperatures in the Martian upper atmospheres, Geophys. Res. Lett., 5, 989-992.

Kallio, E., and P. Janhunen (2001), Atmospheric effects of proton precipitation in the Martian atmosphere and its connection to the Mars-solar wind interaction, J. Geophys. Res., 106, 5617-5634.

Keating, G. M., et al. (1998), The structure of the upper atmosphere of Mars: In situ accelerometer measurements from Mars Global Surveyor, Science, 279, 1672-1676.

Kliore, A. J., and L. F. Mullen (1989), Long term behavior of the main peak of the dayside ionosphere of Venus during solar cycle 21 and its implications on the effect of the solar cycle upon the electron temperature in the main peak region, J. Geophys. Res., 94, 13,339-13,351.

Kliore, A. J., D. L. Cain, G. Fjeldbo, B. L. Seidel, M. J. Sykes, and S. I. Rasool (1972a), The atmosphere of Mars from Mariner 9 radio occultation measurements, Icarus, 17, 484-516.

Kliore, A. J., D. L. Cain, G. Fjeldbo, B. L. Seidel, and S. I. Rasool (1972b), Mariner 9 S-band Martian occultation experiment: Initial results on the atmosphere and topography of Mars, Science, 175, 313-317.

Kliore, A. J., G. Fjeldbo, B. L. Seidel, M. J. Sykes, and P. M. Woiceshyn (1973), S band radio occultation measurements of the atmosphere and topography of Mars with Mariner 9: Extended mission coverage of pola and intermediate latitudes, J. Geophys. Res., 78, 4331-4351.

Knudsen, W. C., K. L. Miller, K. Spenner, V. Novak, R. C. Whitten, and J. R. Spreiter (1979), Thermal structure and energy influx to the day and nightside Venus ionosphere, Science, 205, 105-107.

Kolosov, M. A., O. I. Yakovlev, Y. M. Kruglov, B. P. Trusov, A. I. Effimor, and V. V. Kerzhonovic (1972), Preliminary results of radio occultation studies of Mars by means of the orbiter Mars-2, Dokl. Akad. Nauk. SSSR, 206, $1071-1073$

Kolosov, M. A., et al. (1973), Results of a two-frequency radio occultation of "Mars-2" ionosphere of Mars, Radio Eng. Electron. Phys., Engl. Transl., 18, 1471-1475.

Krasnopolsky, V. A. (2002), Mars' upper atmosphere and ionosphere at low, medium, and high solar activities: Implications for evolution of water, J. Geophys. Res., 107(E12), 5128, doi:10.1029/2001JE001809.

Krasnopolsky, V. A., and P. D. Feldman (2001), Detection of molecular hydrogen in the atmosphere of Mars, Science, 294, 1914-1917.

Levine, J. S., D. S. McDougal, D. E. Anderson, and E. S. Barker (1978), Atomic hydrogen on Mars: Measurements at solar minimum, Science, 200, 1048-1051

Lindal, G. F., H. B. Hotz, D. N. Sweetnam, Z. Shippony, J. P. Brenkal, G. V. Hartsell, R. T. Spear, and W. H. Michael Jr. (1979), Viking radio occultation measurements of the atmosphere and topography of Mars: Data acquired during 1 Martian year of tracking, J. Geophys. Res., 84 , $8443-8456$

Lundin, R., et al. (2006), Ionospheric plasma acceleration at Mars: ASPERA-3 results, Icarus, 182, 308-319.
Ma, Y., A. F. Nagy, I. V. Sokolov, and K. C. Hansen (2004), Threedimensional, multispecies, high spatial resolution MHD studies of the solar wind interaction with Mars, J. Geophys. Res., 109, A07211, doi:10.1029/2003JA010367.

Mahajan, K. K., S. Gosh, R. Paul, and W. R. Hoegy (1994), Variability of the dayside electron temperature at Venus, Geophys. Res. Lett., 21, 77-80.

Martinis, C., J. K. Wilson, and M. J. Mendillo (2003), Modeling day-to-day ionospheric variability on Mars, J. Geophys. Res., 108(A10), 1383, doi:10.1029/2003JA009973.

McElroy, M. B., T. Y. Kong, and Y. L. Yung (1977), Photochemistry and evolution of the Martian atmosphere: A Viking perspective, J. Geophys. Res., 82, 4379-4388.

Mehr, F. J., and M. A. Biondi (1969), Electron temperature dependence of recombination of $\mathrm{O}_{2}^{+}$and $\mathrm{N}_{2}^{+}$ions with electrons, Phys. Rev., 181, 264270 .

Mendillo, M., S. Smith, J. Wroten, H. Rishbeth, and D. Hinson (2003), Simultaneous ionospheric variability on Earth and Mars, J. Geophys. Res., 108(A12), 1432, doi:10.1029/2003JA009961.

Miller, K. L., W. C. Knudsen, K. Spenner, R. C. Whitten, and V. Novak (1980), Solar zenith angle dependence of ionospheric ion and electron temperatures and density on Venus, J. Geophys. Res., 85, 7759-7764.

Nagy, A. F., and T. E. Cravens (2002), Solar system ionospheres, in Atmospheres of the Solar System: Comparative Aeronomy, Geophys. Monogr. Ser., vol. 130, edited by M. Mendillo, A. Nagy, and J. H. Waite, pp. 3954, AGU, Washington, D. C.

Nier, A. O., and M. B. McElroy (1976), Structure of the neutral upper atmosphere of Mars: Results from Viking 1 and Viking 2, Science, $194,1298-1300$

Nier, A. O., and M. B. McElroy (1977), Composition of structure of Mars' upper atmosphere: Results from the neutral mass spectrometers on Viking 1 and 2, J. Geophys. Res., 82, 4341-4349.

Pätzold, M., S. Tellmann, B. Häusler, D. Hinson, R. Schaa, and G. L. Tyler (2005), A sporadic third layer in the ionosphere of Mars, Science, 310 $837-839$.

Pierrard, V. (2003), Evaporation of hydrogen and helium atoms from the atmospheres of Earth and Mars, Planet. Space Sci., 51, 319-327.

Rees, M. H. (1989), Physics and Chemistry of the Upper Atmosphere, Cambridge Univ. Press, New York.

Rishbeth, H., and O. K. Garriott (1969), Introduction to Atmospheric Physics, Elsevier, New York.

Rishbeth, H., and M. Mendillo (2004), Ionospheric layers of Mars and Earth, Planet. Space Sci., 52, 849-852.

Rohrbaugh, R. P., J. S. Nisbet, E. Bleuler, and J. R. Herman (1979), The effect of energetically produced $\mathrm{O}_{2}^{+}$on the ion temperatures of the Martian thermosphere, J. Geophys. Res., 84, 3327-3338.

Schunk, R. W., and A. F. Nagy (2000), Ionospheres: Physics, Plasma Physics, and Chemistry, Cambridge Univ. Press, New York.

Shinagawa, H., and T. E. Cravens (1989), A one-dimensional multispecies magnetohydrodynamic model of the dayside ionosphere of Mars, J. Geophys. Res., 94, 6506-6516.

Shizgal, B., and R. Blackmore (1986), A collisional kinetic theory of a plane parallel evaporating planetary atmosphere, Planet. Space Sci., 34, $279-291$

Stewart, A. I. F. (1987), Revised time dependent model of the Martian atmosphere for use in orbit lifetime and sustenance studies, Rep. NQ 802429, Jet Propul. Lab., Pasadena, Calif.

Stewart, A. I. F., R. R. Meier, L. J. Paxton, S. W. Bougher, and C. G. Fesen (1992), Atomic oxygen in the Martian thermosphere, J. Geophys. Res., 97, $91-102$

Tobiska, W. K. (2004), SOLAR2000 irradiances for climate change, aeronomy and space system engineering, Adv. Space. Res., 34(8), 17361746 .

Torr, M. R., D. G. Torr, R. A. Ong, and H. E. Hinteregger (1979), Ionization frequencies for major thermospheric constituents as a function of solar cycle 21, Geophys. Res. Lett., 6, 771-774

Tyler, G. L., et al. (2001), Radio science observations with Mars Global Surveyor: Orbit insertion through one Mars year in mapping orbit, J. Geophys. Res., 106, 23,327-23,348.

Vasilev, M. B., et al. (1975), Preliminary results of a two frequency occultation study of Mars' atmosphere, Cosmic Res., 13, 41-45.

Wang, J.-S., and E. Nielsen (2003), Behavior of the Martian electron density peak during global dust storms, Planet. Space Sci., 51, 329-338.

Wang, J.-S., and E. Nielsen (2004), Evidence for topographic effects on the Martian ionosphere, Planet. Space Sci., 52, 881-886.

Wilson, R. J. (2002), Evidence for nonmigrating thermal tides in the Mars upper atmosphere from the Mars Global Surveyor Accelerometer Experiment, Geophys. Res. Lett., 29(7), 1120, doi:10.1029/2001GL013975.

Wilson, R. J., D. Banfield, B. J. Conrath, and M. D. Smith (2002), Traveling waves in the northern hemisphere of Mars, Geophys. Res. Lett., 29(14), 1684, doi:10.1029/2002GL014866. 
Withers, P., S. W. Bougher, and G. M. Keating (2003), The effects of topographically-controlled thermal tides in the martian upper atmosphere as seen by the MGS accelerometer, Icarus, 164, 14-32.

Woods, T. N., et al. (2000), TIMED Solar EUV Experiment, Phys. Chem. Earth, 25, 393-396.

Woods, T. N., F. G. Eparvier, S. M. Bailey, P. C. Chamberlin, J. Lean, G. J. Rottman, S. C. Solomon, W. K. Tobiska, and D. L. Woodraska (2005), Solar EUV Experiment (SEE): Mission overview and first results, J. Geophys. Res., 110, A01312, doi:10.1029/2004JA010765.
Zhang, M. H. G., J. G. Luhmann, A. J. Kliore, and J. Kim (1990), A postPioneer Venus reassessment of the Martian dayside ionosphere as observed by radio occultation methods, J. Geophys. Res., 95, 14,82914,839

J. L. Fox and K. E. Yeager, Department of Physics, Wright State University, Dayton, OH 45435, USA. (jane.fox@wright.edu) 